\title{
Visually guided decision making in foraging honeybees
}

\author{
Shaowu Zhang ${ }^{1}$, Aung Si ${ }^{1,2}$ and Mario Pahl ${ }^{3}$ \\ ${ }^{1}$ Centre of Excellence in Vision Science, Research School of Biology, The Australian National University, Canberra, ACT, Australia \\ ${ }^{2}$ Department of Linguistics, School of Culture, History and Language, College of Asia and the Pacific, Australian National University, Canberra, ACT, Australia \\ ${ }^{3}$ BEEgroup, Biocentre, Würzburg University, Würzburg, Germany
}

\section{Edited by:}

Björn Brembs, Freie Universität

Berlin, Germany

Reviewed by:

Benjamin Hayden, University of Rochester, USA

Christoph Grüter, University of Sussex, UK

\section{*Correspondence:}

Shaowu Zhang, Centre of Excellence in Vision Science, Research School of Biology, The Australian National

University, Biology Place, Canberra, ACT 0200, Australia.

e-mail: shaowu.zhang@anu.edu.au
Honeybees can easily be trained to perform different types of discrimination tasks under controlled laboratory conditions. This review describes a range of experiments carried out with free-flying forager honeybees under such conditions. The research done over the past 30 or so years suggests that cognitive abilities (learning and perception) in insects are more intricate and flexible than was originally imagined. It has become apparent that honeybees are capable of a variety of visually guided tasks, involving decision making under challenging situations: this includes simultaneously making use of different sensory modalities, such as vision and olfaction, and learning to use abstract concepts such as "sameness" and "difference." Many studies have shown that decision making in foraging honeybees is highly flexible. The trained animals learn how to solve a task, and do so with a high accuracy, but when they are presented with a new variation of the task, they apply the learnt rules from the earlier setup to the new situation, and solve the new task as well. Honeybees therefore not only feature a rich behavioral repertoire to choose from, but also make decisions most apt to the current situation. The experiments in this review give an insight into the environmental cues and cognitive resources that are probably highly significant for a forager bee that must continually make decisions regarding patches of resources to be exploited.

Keywords: honeybee, top-down, pattern vision, maze learning, learning concept, delayed-matching-to-samples, working memory, long-term memory

\section{INTRODUCTION}

Honeybees are social insects with a rich and easily observable behavioral repertoire, and an excellent capability for learning and memory. For an adult worker bee, successful foraging is the primary task necessary for the survival and maintenance of the whole colony. In order for foraging strategies (i.e., strategies that take into account the time, frequency, and geographic location of foraging, as well as the flowers to be targeted) to be successful, honeybees need to have evolved the sensory and cognitive mechanisms necessary to implement those strategies. Indeed, an individual foraging bee is able to ascertain whether or not it is on the correct path either to a food source or back to the hive, and make any necessary corrections by comparing the currently viewed scene with the appropriate stored image (Collett and Kelber, 1988; Wehner et al., 1990, 1996; Collett et al., 1993; Collett, 1996; Judd and Collett, 1998; Zhang et al., 1999; Pahl et al., 2011). The foragers that find a rewarding food source return to the hive, and dance to inform recruits about the location of the food source. Individual bees following the dance then have to decide whether or not to forage at the food source being advertised (von Frisch, 1967; Esch et al., 2001; Dyer, 2002; Grüter et al., 2008; Menzel et al., 2011). Even while foraging at the advertised location, they have to decide which patches of flowers to visit; such decisions are presumably made after taking into consideration a range of factors, such as shape, color, and time of day, all of which may be influenced by the memories and experiences of past foraging trips. Finally, foraging bees might have to find their way back to the hive from previously unexplored locations. Decision making is undoubtedly required in determining which path to take, and much research has been carried out on the topic of search strategies (Wolf and Hainsworth, 1990; Greggers and Menzel, 1993; Riley et al., 2005). Thus, in every moment of its foraging life, a bee has to continually make numerous decisions that not only ensure that the tasks vital to the colony's well-being are completed, but also that the bee is able to safely return home thereafter.

Honeybees provide a classic example of a symbolic communication system among non-human animals (von Frisch, 1967, 1971). They are able to communicate information by performing dances about potential nesting sites and food sources after scout or forager bees find such locations. In the context of swarming behavior, Seeley and his colleagues have examined the group decision-making process in detail, and shown that in the early stages of swarming, the scout bees locate potential nest sites in all direction and at distances of up to several kilometers. They communicate to each other through dancing, allowing the comparison of different potential sites. Finally, there is a crescendo of dancing just before liftoff. They proposed that a swarm's overall strategy of decision making was a "weighted additive strategy" (Seeley et al., 1991; Seeley and Buhrman, 1999). The evolution and precise workings of such phenomena - which have been observed in a number of invertebrate taxa - are discussed in further detail in the contributions by Jeanson et al. (2012) and Stroeymeyt (2012).

In the present article, we review research, from the last two decades, that has explored the cognitive processes involved in 
decision making in honeybees. This review focuses on individual, free-flying honeybees trained to perform complex, artificial tasks in a laboratory setting. These experiments therefore attempt to explain the factors that govern the behavior of foraging honeybees, as they navigate to a precise location (which may be known from a previous trip, or unknown), and make decisions regarding which patches of flowers (or even which individual flowers) should be preferentially targeted for nectar or pollen. Visually based tasks dominate our experimental protocols, although some olfactory cues are infrequently used to test for the transfer of learnt rules across sensory modalities (The contribution by Ritzmann et al. (2012) provides an account of interactions between tactile and visual sensory input in cockroach decision making). The experiments described in this review illustrate how honeybees use not only bottom-up sensory information (i.e., information from their immediate physical environment), but also memorized top-down information (i.e., stored conceptual information) in decision making (Zhang and Srinivasan, 1994). They are able to use abstract visual features of objects to make a decision in discrimination tasks, make a series of decisions while negotiating a complex maze, and learn abstract concepts or rules that guide them toward making correct decisions. In Delayed-Matching-toSample (DMTS) tasks or Symbolic Delayed-Matching-to Sample (SDMTS) tasks, they have to use a combination of working memory and long-term-memory to make a correct decision.

\section{MEMORIZED INFORMATION IS ACTIVELY INVOLVED IN DECISION MAKING}

Like big animals, bees can learn to distinguish camouflaged patterns if they are first trained on a related, but simpler task. This demonstrates that bees apply acquired prior "knowledge" in decision making, and use it to choose the correct camouflaged pattern (Zhang and Srinivasan, 1994).

It is well-known that prior knowledge or experience aids us tremendously in uncovering objects that are poorly visible, partially hidden, or camouflaged. Many of us who view the scene in Figure 1 for the first time would not see a familiar object, especially if we are unaware of the picture's content. Once the camouflaged Dalmatian has been discovered, however, it is detected and recognized instantly every time the picture is re-encountered. Evidently, prior experience or knowledge aids the visual system significantly in the task of uncovering objects (Lindsay and Norman, 1977; Goldstein, 1989; Cavanagh, 1991).

"Top-down" processing of this kind can speed up the analysis of the retinal image when a familiar scene or object is encountered, and help fill-in, or complete, details that are missing in the optic array (Cavanagh, 1991). Is the ability to enhance processing in this way restricted to highly developed visual systems, such as those of humans and higher mammals? Or does it extend to relatively simple visual systems, such as those of invertebrates?

Zhang and Srinivasan (1994) approached this question by investigating whether bees are able to use prior experience to facilitate the detection of objects and discrimination of their shapes. They first attempted to train bees to distinguish between two shapes - a ring and a disk - when each shape was presented in a camouflaged fashion as a textured figure, positioned $6 \mathrm{~cm}$ in front of a similarly textured background in a Y-maze (Figures 2A,B). It

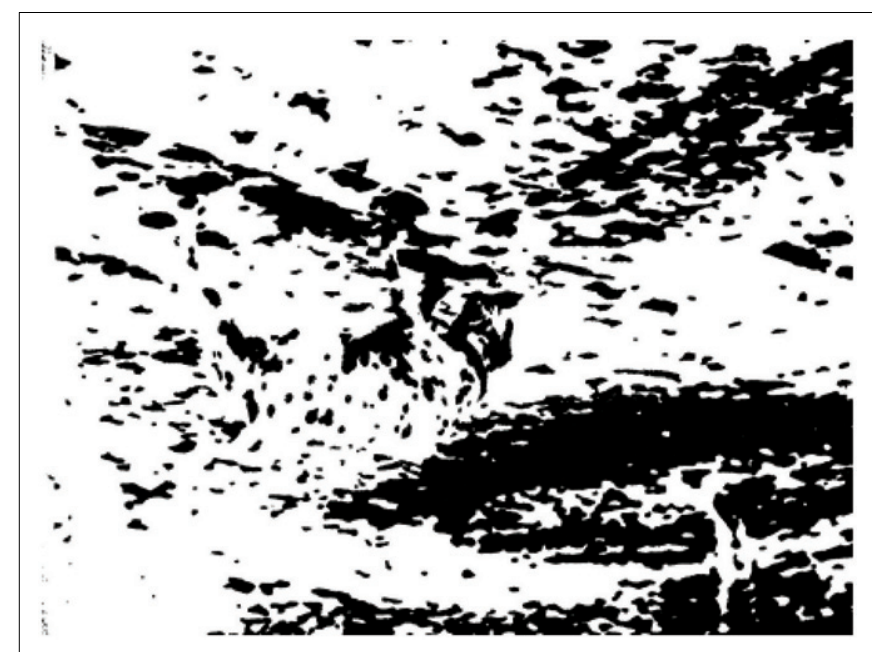

FIGURE 1 | A familiar, but camouflaged object (readers experiencing difficulty in recognizing the Dalmatian dog may wish to view the picture upside-down). Photo courtesy R. C. James. Reprinted from Lindsay and Norman (1977), with permission of authors and publishers.

turned out that bees were unable to learn to make this discrimination, despite lengthy training incorporating over 100 rewards per bee. Next, Zhang and Srinivasan examined whether bees could learn to distinguish the camouflaged patterns if they were first trained on a related, but simpler task: that of distinguishing between a black ring and a black disk, each presented $6 \mathrm{~cm}$ in front of a white background. The ring and the disk were of the same size and shape as their textured counterparts, and their spatial configuration in relation to the background was identical to that in the previous experiment. The bees were able to learn this new task (Figure 2C). When these pre-trained bees were tested on the task of Figure 2B, they could distinguish between the patterns almost immediately (Figure 2D). Although the figures in Figure 2D are camouflaged, they can be detected by virtue of the relative motion between the images of the figure and the more distant background, as the bee approaches the figure. Evidently, the bees were able to learn to use this motion parallax as a cue to break the camouflage - but only after they had been pre-trained on uncamouflaged versions of the same shapes.

\section{BEES ARE ABLE TO USE ABSTRACT, GENERAL PROPERTIES OF VISUAL PATTERNS IN DISCRIMINATION TASKS CHOOSING THE CORRECT PATTERN}

What kind information can be stored in a honeybee's memory? Honeybees are able to use concrete features of objects, such as color, shape, scent, and so on (Menzel and Bitterman, 1983; Gould and Gould, 1988; Menzel, 1990; Chittka et al., 1993; Lehrer et al., 1995). Important insights into visual perception can be gleaned by examining whether honeybees are capable of perceiving and abstracting the general properties of objects. There can be little doubt that bees use some kind of neural "snapshot" to remember and recognize patterns and landmarks (Collett and Cartwright, 1983; Judd and Collett, 1998). However, it is hard to imagine that this is all there is to pattern recognition. In their daily lives, bees are required to remember a number of different patterns and 


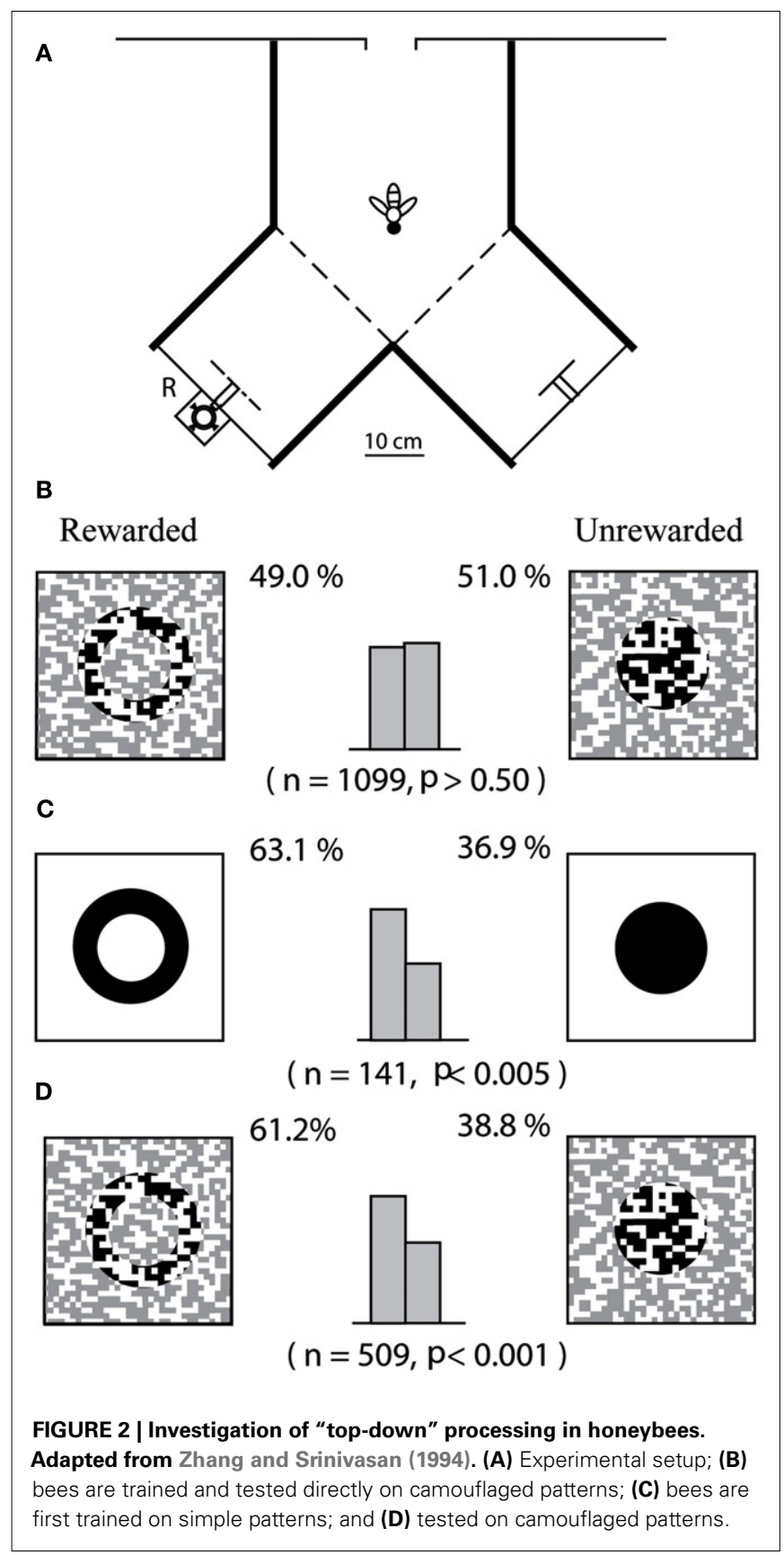

their properties. Some examples would be the shape of the nest or hive, shapes representing nectar-bearing flowers, and shapes of important landmarks on the way to the food source and back. If snapshots were the only mechanisms for remembering shapes, bees would require a large memory to store all of these images (Horridge et al., 1992). Given that the brains of bees contain far fewer neurons than do ours, it seems very unlikely that they can afford the luxury of a large memory. One would imagine, therefore, that bees also possess other, more economical means of representing patterns. Can bees extract general properties of form? We tackled this question in the early 1990s with a series of Y-maze experiments.

\section{Learning to abstract pattern orientation}

It is of interest to ask whether honeybees can learn to abstract a particular attribute of a pattern, such as its orientation, without having to memorize the pattern precisely. An early paper by Wehner (1971) hinted that bees could indeed abstract pattern orientation in this way. This question was pursued further by Van Hateren et al. (1990), who used a Y-maze apparatus and stimuli consisting of black-and-white gratings of random amplitude.

Van Hateren et al. (1990) found that bees could be trained to distinguish between the vertical and horizontal orientations, as well as between two oblique directions. Furthermore, bees trained to distinguish between two mutually perpendicular orientations were able to discriminate the overall orientations of other patterns which they had never encountered previously. Thus, bees are able to extract orientation information from patterns on which they are trained, and to use this information to evaluate novel patterns in decision making.

Similarly, honeybees are capable of discriminating patterns with radial symmetry from circular symmetry (Horridge and Zhang, 1995), as well as with vertical symmetry from horizontal symmetry (Horridge, 1996). Giurfa et al. (1996) showed that bees can learn to discriminate bilaterally symmetrical patterns from non-symmetrical ones; bees can also learn other abstract properties of objects, such as their color and size, without having to memorize the objects' images exactly (Horridge et al., 1992; Ronacher, 1992).

It is important to emphasize that, in all of the above experiments the ability to "generalize" has been demonstrated by training bees to not one, but a number of stimuli that differ individually in detail but share the property that is to be generalized. For example, the rewarded patterns could all possess the same orientation or the same kind of symmetry (say, left-right symmetry). These stimuli are shuffled randomly during the training. Such a training procedure ensures that the bees learn the critical cue that is associated with the reward (Horridge, 1999).

\section{HONEYBEES ARE ABLE TO MAKE A SERIES OF DECISIONS IN NEGOTIATING COMPLEX MAZES}

The discovery of "top-down processing" by bees inspired us to pursue further investigation of their learning and memory. We subsequently initiated a series of experiments, using mazes, to examine whether honeybees can learn "rules" in making a series of decisions to deal with complex tasks and then to apply them to novel situations.

The ability to learn mazes has been investigated extensively in a number of higher vertebrates, notably rats, mice, and pigeons (Pick and Yanai, 1983; Dale, 1988). Relatively few studies, however, have explored the capacity of invertebrates to learn mazes. Can bees learn complex labyrinths, requiring several correct decisions to be made to reach the goal? Zhang et al. (1996) explored this question by attempting to train bees to fly through a variety of complex mazes to find a reward of sugar solution, in the presence, or absence of specific visual cues. Each maze consisted of a $4 \times 5$ matrix of identical cubic boxes. Each wall of a box carried a hole in its center. The path through the maze was created by leaving open some of the holes between boxes, and blocking others. Bees had to fly through a sequence of boxes to reach the goal, which 
was a feeder containing sugar solution. The experimental maze was placed on a movable table and its position and orientation were varied frequently to prevent the bees from using landmarks external to the maze as navigational cues.

\section{Honeybees are able to negotiate a maze by following a mark}

One series of experiments investigated the ability of bees to find their way through the maze by learning to following a color mark that signaled the correct exit in each box. The mark was a $4 \mathrm{~cm} \times 4 \mathrm{~cm}$ green square affixed immediately below the appropriate hole in each box to indicate the correct path (Figure 3A). Bees were trained to enter the maze and take the correct path through it. This was accomplished by moving a feeder step-by-step along the correct path, until it reached the third box in the path. During this period, the bees had the opportunity to learn that the mark in each box signaled the correct exit. After the bees had reached this stage, the feeder was moved directly to the final box on the path, left there briefly, and then moved to its final destination, namely, the feeder compartment behind the final box.

The bees' performance was tested immediately thereafter. During the test, only one bee at a time was allowed into the maze.

The results show clearly that bees, trained initially to follow color marks through only a small, initial part of the maze, are immediately able to "blaze a trail" by using the same cue to find their way through the rest of the maze (Test 1 in Figure 3B). Performance continues to be good when the bees are tested on a new path, created by rearranging the boxes and marks (Test 2 in Figure 3B). Evidently, the trained bees had learnt to follow the

A

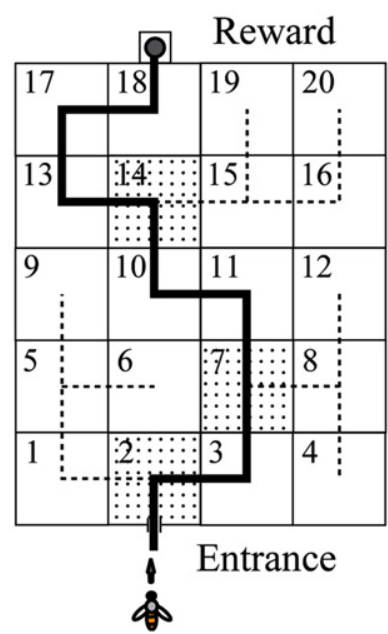

Correct path

- - - Incorrect path

$:: \quad$ Decision boxes

on correct path

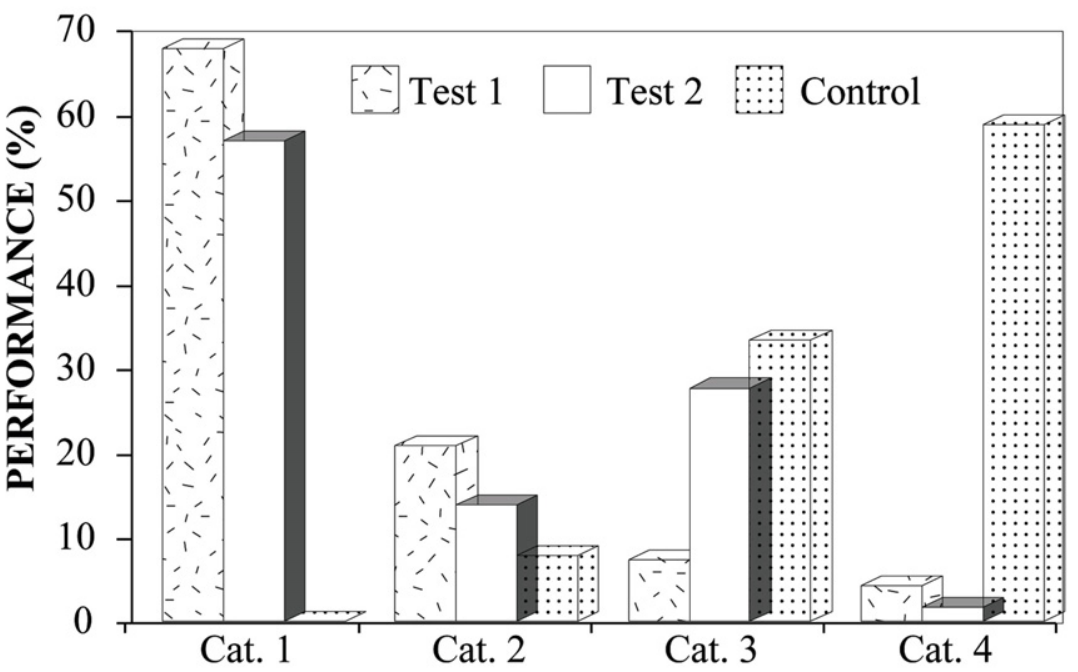

CATEGORY

FIGURE 3 | Learning to negotiate mazes by following marks.

Modified from Zhang et al. (1996). (A) The experimental setup, indicating the correct path through the maze; (B) Experimental results. Performance was scored by assigning each flight into one of four categories. Cat. 1: a bee flew through the entire path and arrived at the goal without making any mistakes; Cat. 2: flights in which the bee turned back and retraced her path (once or many times) but remained on the correct path; Cat. 3: flights in which a bee made one or more wrong turns at the decision boxes, but still arrived at the goal within 5 min; Cat. 4: unsuccessful searches, defined as flights in which the bee did not reach the goal within 5 min of entering the maze (regardless of whether she was on the correct path or not). 
marks to the goal and were immediately able to use this rule to trace a novel path through the maze.

\section{Honeybees are able to negotiate a maze by using a symbolic cue}

Another series of experiments examined whether bees could learn to negotiate mazes by using a symbolic cue (Zhang et al., 1996). Left and right turns were signaled according to a color placed on the back wall of each box where a turn had to be made (Figure 4A, left panel). Bees were trained and tested for learning performance in a specific path (Figure $\mathbf{4 A}$, left-hand panel, Path 3 ). The training and testing procedures were similar to those described above. The results showed that bees learned this task very well too (Test 3, Figure 4B). In fact, their performance in this maze was just as impressive as in the mark-following maze. Here again, bees trained to use the symbolic cue on a particular route were immediately able to use the cue to trace novel paths (Figure 4A, middle and right-hand panels) though the maze (Test 4 and 5, Figure 4B). The performance in all tests (Test 3 , Test 4 , and Test 5) was significantly better than in the control (Figure 4B).

\section{Honeybees negotiate unmarked mazes}

Zhang et al. (1996) have also explored the ability of bees to learn to negotiate unmarked mazes. Here bees were trained step-by-step through the entire path, from the entrance to the reward box. After training for 5 days, tests carried out on the same path revealed that the bees had indeed learnt to find their way through the maze, although performance was significantly poorer than when they followed a color mark. Nevertheless, performance was significantly better than the control. Presumably, this is accomplished by memorizing the sequence of turns that have to be made at specific distances (or box counts) along the route. There is evidence that bees use visual odometry to estimate distance flown (Srinivasan

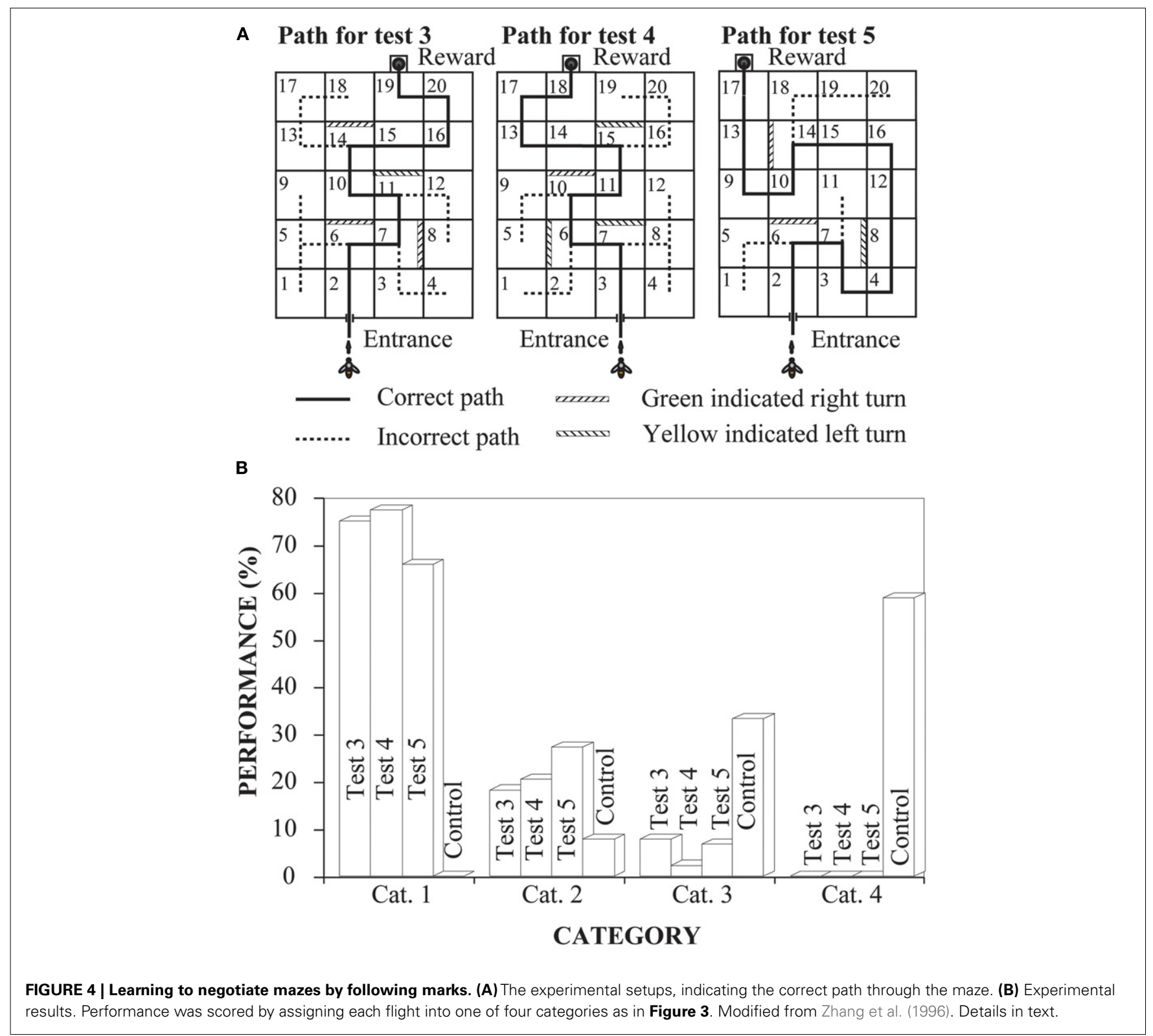


et al., 1997, 2000) and that they are even able to "count" landmarks en route to a goal (Chittka and Geiger, 1995).

Interestingly, when bees that have learned to negotiate a maze with the aid of marks or symbolic cues (as in the experiments of Figures 3 and 4 ) are tested on the same routes with the marks or cues removed, their performance is significantly poorer than when bees are trained on unmarked routes in the first place (Zhang et al., 1996). Evidently when bees are given marks or symbolic cues, they rely almost exclusively on these signals for navigation: they hardly pay any "attention" to the route that they take through the maze, unlike the bees that are forced to learn an unmarked route.

\section{Honeybees negotiating mazes by using path regularity}

We have seen above that the bees' performance in the unmarked maze was not as good as that in the mazes with color marks, where there was information on the appropriate turn to be made at each stage in the maze. This is because the only way that a bee can navigate an unmarked maze, in general, is to memorize the path through it - that is, memorize the entire sequence of turns that are necessary to go through the maze successfully. It is conceivable, however, that some unmarked mazes are easier to learn than others. For example, mazes that require a regular pattern of turning might be learned more readily than those that do not, if bees possess the ability to recognize such patterns.

Zhang et al. (2000) explored this question by investigating the ability of bees to learn unmarked mazes of various configurations, some of them with path regularity and some of them without it. Four different configurations were used, each in a different experimental series: (a) constant-turn mazes, in which the appropriate turn is always in the same direction in each decision chamber; (b) zig-zag mazes, in which the appropriate turn is alternately left and right in successive decision chambers; (c) irregular mazes, in which there is no readily apparent pattern to the turns; and (d) variable irregular mazes, in which the bees were trained to learn four irregular mazes simultaneously (Figure 5).

A bee flying a correct path through the maze entered a cylinder through one hole and could leave through one of two exit holes, positioned $45^{\circ}$ to the left and right of the "straight ahead" direction. One of these holes represented the correct path continuing through the maze, while the other one led to a cylinder representing a "dead-end." The final cylinder on the correct path contained a feeder that provided a solution of sugar water, which the bees could drink ad libitum. After they had fed, bees were released from this cylinder by raising the transparent cover of the cylinder temporarily. The bees' performance under the various experimental conditions was evaluated by using the same categories as described in Figure 3, as well as flight time through the maze.

\section{Learning to negotiate a right-turn maze}

One series of experiments (noted as Series 1 in the Tables) investigated the ability of bees to negotiate a maze in which every turn is to be made in the same direction - a constant-turn maze. A rightturn maze is shown in Figure 5A. The performance of bees, trained on this maze for 1 day, and then tested in an identical maze is summarized in Table 1, as evaluated by the four categories, and in Table 2, as evaluated by the five time categories. The performance shows that most flights have a relatively short duration (T1: flight duration $<30 \mathrm{~s}$ ) and most of the test flights belong to the category Cat. 1 (no errors). Thus, the trained bees are able to fly through the maze quickly and accurately.

Bees trained in the right-turn maze (Figure 5A) were tested in an extended right-turn maze with an additional decision chamber added at the end, also requiring a right turn. These bees showed a clear tendency to make correct choices (right turns) even in the extension, indicating that they applied the rule that they had learned during the training to the extended part of the maze in this test. Bees trained in the right-turn maze were tested in an irregular maze, which they had never experienced (Figure 6A). Interestingly, these bees succeeded in arriving at the feeder, as shown by the sample trajectory in Figure 6A. They achieved this by simply using the "always turn right" rule. This rule always made them reach the goal eventually, even if they entered some dead-end chambers en route. The relative frequencies of right and left turns made by the trained bees, when tested in a number of irregular mazes are shown in Figure 6B. Bees trained in a right-turn maze show a strong and significant preference for making right-hand turns, no matter what maze they encounter. Bees trained in a right-turn maze can also negotiate left-turn and zig-zag mazes, because the right-turn rule (or left-turn rule, for that matter) can, in principle, be applied to all of these mazes to eventually get to the reward, even though this entails entering a number of dead-end cylinders en route (Zhang et al., 2000).

\section{Learning to negotiate a zig-zag maze}

The second series of experiments (noted as Series 2 in the Tables) examined whether bees could learn to negotiate a zig-zag maze, where the correct turns were alternately to the right and to the left, as shown in Figure 5B. It was shown that, bees learn a zig-zag maze nearly as well as a constant-turn maze (Zhang et al., 2000). Can bees extrapolate the zig-zag rule that they have learned, and apply it to extended or altered mazes? We investigated this question by testing the bees that were trained in the zig-zag maze of Figure 5B, in a set of altered mazes - one of these experiments is discussed below.

Bees were tested in a maze similar to that of Figure 5B, but in which a special chamber (chamber 5) was added in the middle, as shown in Figure 7A. However, this new chamber had only one exit, diametrically opposite to the entrance, so that the bees could not choose "left" or "right" while passing through it. The question here was: how would the bees behave in the next chamber (chamber 7), given that they had made a left turn in the previous chamber (chamber 5). The tests (Figure 7B) revealed that the bees showed a clear tendency to turn left in chamber 7. This implies that they had treated chamber 5 as though they had made a right turn in it, even though it was a "dummy" chamber that offered no turning choice. Evidently, in applying the zig-zag rule, even dummy chambers are treated as valid ones.

The above experiments show that honeybees can negotiate mazes by recognizing and learning regularities in the paths through them, if such regularities exist. The performance in the mazes with path regularities is better than in the mazes without path regularities (for details of statistical tests see Zhang et al., 2000). Honeybees can negotiate novel mazes in transfer tests by using the "rules" that they acquire during training. 
A

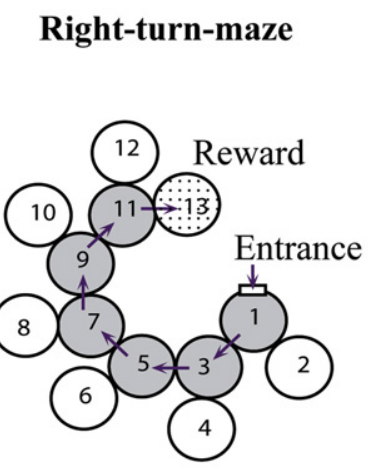

Correct path: $1>3 \rightarrow 5 \rightarrow 7$ $\rightarrow 9 \rightarrow 11 \rightarrow 13$

\section{B}

Zig-zag maze

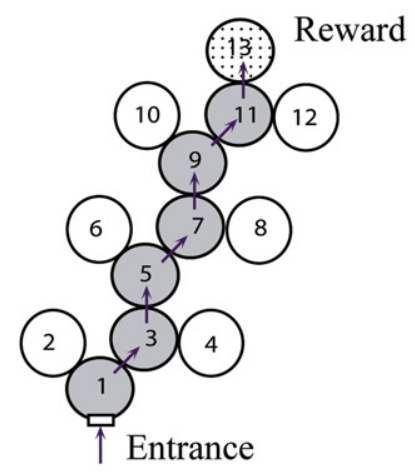

Correct path: $1>3 \rightarrow 5 \rightarrow 7$

$\rightarrow 9 \rightarrow 11 \rightarrow 13$
C
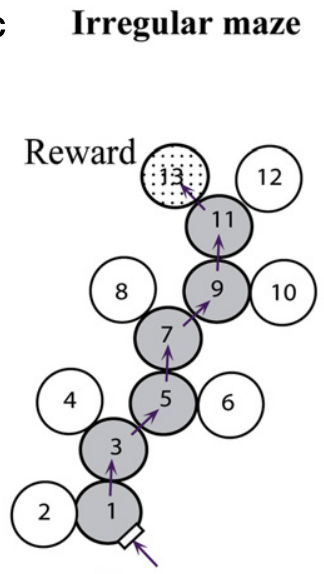

Entrance

Correct path: $1>3 \rightarrow 5 \rightarrow 7$

$\rightarrow 9 \rightarrow 11 \rightarrow 13$

\section{Variable configuration}

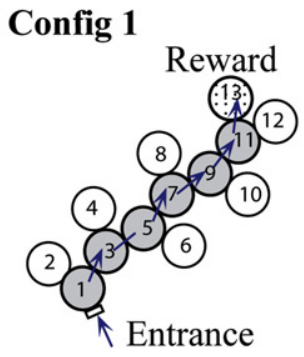

Config 3

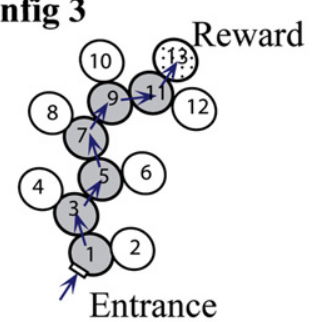

Config 2

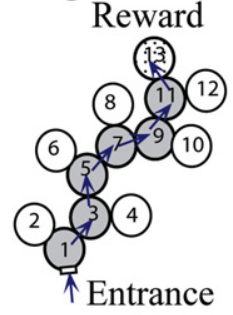

Config 4

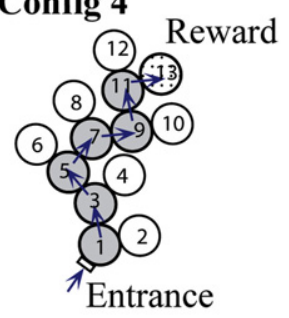

Correct path: $1 \rightarrow 3 \rightarrow 5 \rightarrow 7$

$$
\rightarrow 9 \rightarrow 11 \rightarrow 13
$$

FIGURE 5 | Four types of maze configurations. (A) Constant-turn maze: same turn direction in each decision chamber. (B) Zig-zag maze: alternating turns in successive decision chambers. (C) Irregular maze: random

\section{HONEYBEES USE WORKING MEMORY AND LONG-TERM-MEMORY IN DELAYED-MATCH-TO-SAMPLE TASKS OR SYMBOLIC-DELAYED-MATCH-TO-SAMPLE TASKS}

One of the more complex tasks that has been used to investigate principles of learning and memory is the so-called "DMTS." This task has been investigated in a number of vertebrate species such as the monkey (e.g., D'Amato et al., 1985), dolphin (e.g., Herman and Gordon, 1974), and pigeon (e.g., Roberts, 1972). Honeybees need to use two memory systems to successfully complete this task: working memory for remembering a sample pattern, and sequence of turns. (D) Variable irregular mazes: four configurations have to be learned simultaneously. Modified from Zhang et al. (2000). Details in text. long-term-memory for remembering what criterion or rules are to be used in making decisions.

Most DMTS tasks follow the same general procedure. Each trial begins with the presentation of a sample stimulus. The sample is followed by a delay or retention interval and then by the presentation of two or more test stimuli, one of which is identical to the sample stimulus. If the animal chooses the test stimulus that corresponds to the sample, it then obtains a reward (hence, the name "delayed match-to-sample"). Most experiments use two or three sample stimuli, which are varied randomly from trial to trial. 
Table 1 | Summary of maze performance as evaluated by categories.

\begin{tabular}{|c|c|c|c|c|c|c|}
\hline & T1 & T2 & T3 & T4 & T5 & Total \\
\hline \multicolumn{7}{|l|}{ SERIES 1} \\
\hline Number of flights & 138 & 78 & 30 & 13 & 7 & 266 \\
\hline Percentage & 51.8 & 29.3 & 11.3 & 4.9 & 2.6 & \\
\hline \multicolumn{7}{|l|}{ SERIES 2} \\
\hline Number of flights & 64 & 45 & 11 & 3 & 0 & 123 \\
\hline Percentage & 52.0 & 36.6 & 8.9 & 2.4 & 0 & \\
\hline \multicolumn{7}{|l|}{ SERIES 3} \\
\hline Number of flights & 39 & 49 & 27 & 10 & 0 & 125 \\
\hline Percentage & 31.2 & 39.8 & 21.6 & 8.0 & 0 & \\
\hline \multicolumn{7}{|l|}{ SERIES 4} \\
\hline Number of flights & 7 & 23 & 11 & 3 & 12 & 56 \\
\hline Percentage & 12.5 & 41.1 & 19.6 & 5.4 & 21.4 & \\
\hline \multicolumn{7}{|l|}{ CONTROL } \\
\hline Number of flights & 3 & 13 & 10 & 3 & 13 & 42 \\
\hline Percentage & 7.1 & 31.0 & 23.8 & 7.1 & 31.0 & \\
\hline
\end{tabular}

For each series of experiments, performance is indicated by number and percentage of flights in each category: Cat. 1 to Cat. 4 (see Figure 6 caption for details).

Table 2 | Summary of maze performance as evaluated by flight time.

\begin{tabular}{|c|c|c|c|c|c|}
\hline & Cat. 1 & Cat. 2 & Cat. 3 & Cat. 4 & Total \\
\hline \multicolumn{6}{|l|}{ SERIES 1} \\
\hline Number of flights & 87 & 18 & 161 & 0 & 266 \\
\hline Percentage & 32.7 & 6.8 & 60.6 & 0 & \\
\hline \multicolumn{6}{|l|}{ SERIES 2} \\
\hline Number of flights & 33 & 4 & 86 & 0 & 123 \\
\hline Percentage & 26.8 & 3.3 & 69.9 & 0 & \\
\hline \multicolumn{6}{|l|}{ SERIES 3} \\
\hline Number of flights & 21 & 5 & 99 & 0 & 125 \\
\hline Percentage & 16.8 & 4.0 & 79.2 & 0 & \\
\hline \multicolumn{6}{|l|}{ SERIES 4} \\
\hline Number of flights & 0 & 1 & 55 & 0 & 56 \\
\hline Percentage & 0 & 1.8 & 98.2 & 0 & \\
\hline \multicolumn{6}{|l|}{ CONTROL } \\
\hline Number of flights & 1 & 0 & 34 & 7 & 42 \\
\hline Percentage & 2.4 & 0 & 80.9 & 16.7 & \\
\hline
\end{tabular}

For each series of experiments performance is indicated by number and percentage of flights in each time category (the time taken to successfully navigate the test maze) -T1: 1-30 s; T2: 31-60 s; T3: 61-90 s; T4: 91-120 s; and T5: 121-300 s (5 min). 11 therefore represents the best performance and T5 the worst.

A more complex variant of the above task is called a "SDMTS" task. In this task, none of the test stimuli physically match the sample: the experimenter arbitrarily designates the correct choice. Here, the animal has to learn to associate the correct test stimulus corresponding to each sample stimulus.

Can bees learn such tasks? Their foraging behavior may give us some hints. Honeybees have evolved a number of navigational skills that enable successful foraging. Collett and Wehner suggested that foraging insects traveling repeatedly to a food source and back

\section{A Transfer test in an irregular maze}

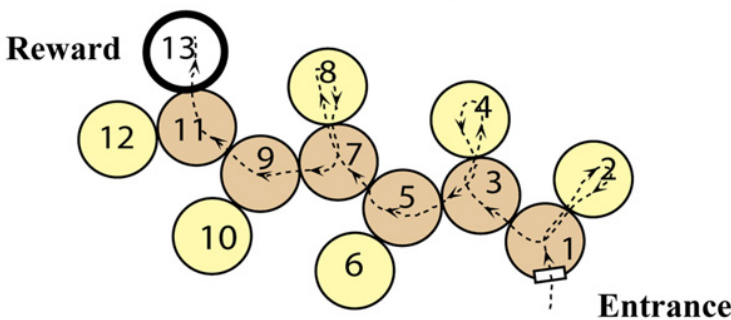

Flight trajectory: $1 \rightarrow 2 \rightarrow 1 \rightarrow 3 \rightarrow 4$

$\rightarrow 3 \rightarrow 5 \rightarrow 7 \rightarrow 8 \rightarrow 7 \rightarrow 9 \rightarrow 11 \rightarrow 13$

\section{B Performance in Transfer tests}

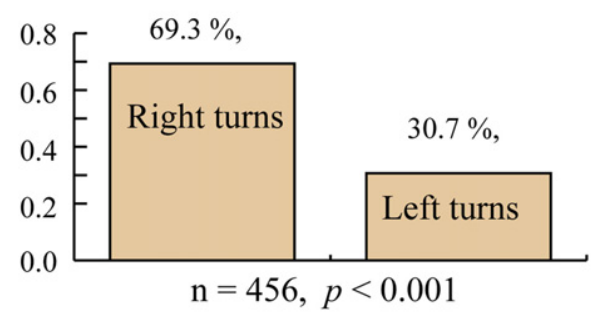

FIGURE 6 | Training in a right turn maze and transfer test in an irregular maze. (A) Transfer test setup. (B) Test results. Modified from Zhang et al, (2000). Details in text

to their homes navigate by using a series of visual images, or "snapshots," of the environment acquired en route (Collett and Kelber, 1988; Wehner et al., 1990, 1996; Collett et al., 1993; Collett, 1996; Judd and Collett, 1998). By comparing the currently viewed scene with the appropriate stored image, the insect is able to ascertain whether or not it is on the correct path, and make any necessary corrections. Successful foraging may require the bee to be able to solve tasks analogous to SDMTS tasks. Thus, it is of interest to explore whether bees can learn DMTS and SDMTS tasks.

\section{Learning Symbolic-Delayed-Matching-To-Sample task in the visual domain}

One series of experiments examined the bees' ability to learn an SDMTS task in the visual domain (Zhang et al., 1999). Honeybees were trained to fly through a compound Y-maze consisting of a series of interconnected cylinders (Figure 8A). The first cylinder carried the sample stimulus.

The second and third cylinders each had two exits. Each exit carried a visual stimulus, between which the bees had to choose. If a bee made a correct choice in the second as well as in the third cylinder, she arrived in a fourth cylinder where she found a feeder with sugar solution. Thus, the second and the third cylinder acted as decision stages: at each of these cylinders the bee had to choose between two stimuli. It was the single sample stimulus in the first cylinder that determined the choices that the bees had to make in the subsequent decision stages.

During training, the sample stimulus was a black-and-white grating oriented either horizontally (Stimulus A) or vertically (Stimulus $\mathrm{A}^{\prime}$ ), respectively. The second cylinder (first decision 


\section{Transfer test in augmented zig-zag maze}

\section{A Maze configuration}

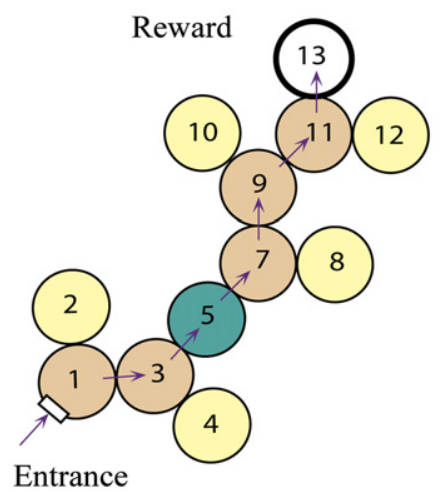

Correct path: $1 \rightarrow 3 \rightarrow 5 \rightarrow 7$

\section{B Sequential performance histogram}

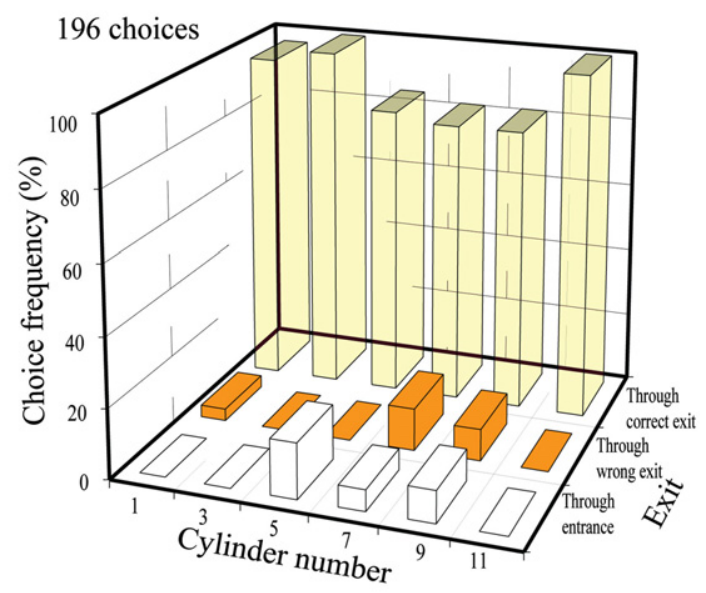

FIGURE 7 | Training in a zig-zag maze and transfer test in an augmented zig-zag maze. (A) Configuration of the augmented zig-zag maze, with an additional cylinder. (B) Histogram showing performance at each decision cylinder. Adapted from Zhang et al. (2000). Details in text.

stage) offered a choice between a blue square (Stimulus B) and a green one (Stimulus $\mathrm{B}^{\prime}$ ), and the third cylinder a choice between a pattern consisting of a sectored disk (C) or of concentric rings $\left(C^{\prime}\right.$; Figure 8B). When the sample stimulus was the horizontal grating, the feeder could only be reached if the bee chose blue in the second cylinder and the sectored disk in the third. However, when the sample was the vertical grating, the bee could reach the reward only if she chose green in the second cylinder and the ring pattern in the third.

After training, the bees were tested not only on the training sequences $\mathrm{ABC}$ and $\mathrm{A}^{\prime} \mathrm{B}^{\prime} \mathrm{C}^{\prime}$ (learning tests; Figure 8B), but also in transfer tests which presented five other permutations of the training sequences. The results of tests on one of the permuted sequences (BAC and $\mathrm{B}^{\prime} \mathrm{A}^{\prime} \mathrm{C}^{\prime}$ ) are illustrated in Figure 8C.

The results showed that bees are indeed capable of learning SDMTS tasks. Clearly, viewing the sample stimulus (horizontal or vertical grating) triggers recall of the stimulus that should be chosen in each of the subsequent stages (Figure 8B). Furthermore, the trained bees continued to choose the appropriate stimulus at each stage of the maze even in the transfer test (Figure 8C), as well in tests using other sequence permutations (Zhang et al., 1999). These findings indicate that, in general, exposure to any one of the stimuli that were encountered in the training $\left(A, B, C, A^{\prime}, B^{\prime}, C^{\prime}\right)$ was sufficient to trigger associative recall of all of the other stimuli belonging to that set. In all of the tests, changing the sample stimulus (from $\mathrm{A}$ to $\mathrm{A}^{\prime}, \mathrm{B}$ to $\mathrm{B}^{\prime}$, or $\mathrm{C}$ to $\mathrm{C}^{\prime}$ ) caused the bees to change (and reverse) their preference for the stimuli that they encountered at subsequent stages of the maze. It should be noted that, in this experiment, the bees were not specifically trained to distinguish between $\mathrm{A}$ and $\mathrm{A}^{\prime}$, which were the sample stimuli in the training. Nevertheless, the bees distinguished between them in the transfer tests because they associated them with the stimulus sets $\mathrm{ABC}$ and $\mathrm{A}^{\prime} \mathrm{B}^{\prime} \mathrm{C}^{\prime}$, respectively. It is also clear from this set of tests that the bees were capable of treating the stimulus pairs $\left(\mathrm{B}, \mathrm{B}^{\prime}\right.$; Figure $8 \mathrm{C}$ ) as well as $\left(\mathrm{C}, \mathrm{C}^{\prime}\right.$; not shown in the figure) as sample stimuli, even though these were never encountered as sample stimuli in the training.

The above findings suggest that bees solve the SDMTS task by mapping the six visual stimuli that they encounter in the training into two distinct sets $(\mathrm{A}, \mathrm{B}, \mathrm{C})$ and $\left(\mathrm{A}^{\prime}, \mathrm{B}^{\prime}, \mathrm{C}^{\prime}\right)$, as illustrated in Figure 9 After training, exposure to any stimulus belonging to a member of one of these sets triggers recall of the other two members belonging to that set. Thus exposure to $\mathrm{B}$, for example triggers recall of $A$ and $C$; whereas exposure to $C^{\prime}$ triggers recall of $\mathrm{A}^{\prime}$ and $\mathrm{B}^{\prime}$.

\section{Learning the Symbolic-Delayed-Matching-To-Sample task across sensory modalities}

Can bees learn an SDMTS task when they are required to make associations that span different sensory modalities? Clearly, humans display impressive cross-modal associative recall. It is a common experience that a smell or a sound can trigger a vivid recollection of an associated event in the past - even if it involves a different sensory modality, and even if the episode occurred a long time ago (Baddley, 1983).

Srinivasan et al. (1998) explored this capacity by asking whether bees could learn to associate specific scents with specific colors. The apparatus consisted of a compound Y-maze, as in the above experiments, but with a single decision stage (Figure 10A). The sample stimulus, presented in the first cylinder, was a scent that was either lemon or mango. The decision stage offered a choice of two colors, blue or yellow. When the bees encountered lemon at the entrance, they had to learn to choose blue in the decision stage; when they encountered mango, they had to choose yellow. The bees learned this task very well (Figure 10B Experiment 1). The scent of lemon evidently evoked recall of blue, whereas mango 


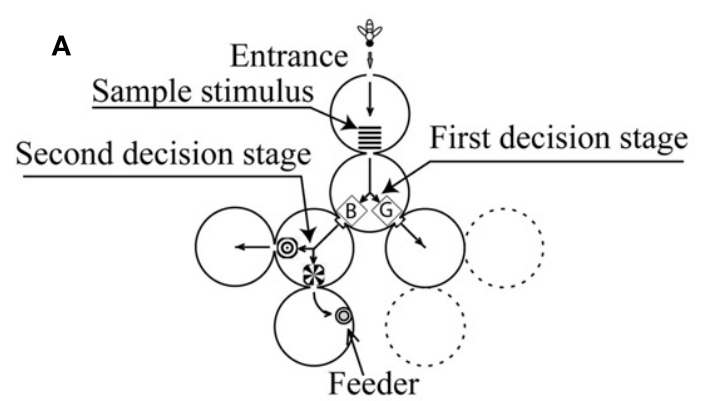

B

Sample
stimulus

First decision stage

Second decision stage

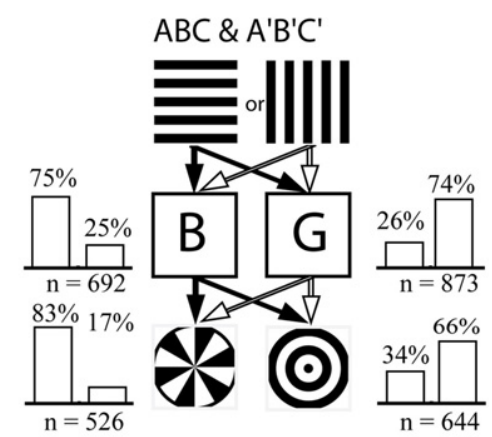

C

Sample

stimulus

First decision stage

Second decision stage

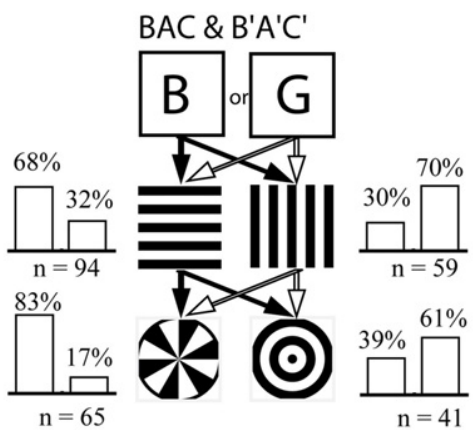

FIGURE 8 | Learning a symbolic-delayed-matching-to-sample task in the visual modality. (A) $Y$-maze setup with two decision stages. (B) Training stimulus configuration and training performance. The bees learned to choose horizontal-blue-sector or vertical-green-ring associations in order to get a reward. (C) Stimulus configuration and performance on the transfer test. Modified from Zhang et al. (1999). Details in text.

triggered recall of yellow. Bees could also be trained to make the opposite associations: lemon with yellow, and mango with blue (Figure 10B, Experiment 2), as well as symbolic matches in the opposite direction (Figures 10C,D).

The evidence presented here clearly shows that honeybees are able to learn SDMTS tasks, not only in the visual modality, but also across sensory modalities. Learning an SDMTS task requires that the bee be able, when presented with a sample stimulus, to recall other stimuli that are associated with the sample stimulus. For a foraging honeybee, cross-modal associative recall can facilitate the search for a food source. For example, detecting the scent of lavender could initiate a search for purple flowers.

\section{Learning the concepts of "sameness" and "difference"}

A related question is whether honeybees are able to group stimuli according to certain rules, or concepts, such as "sameness" or

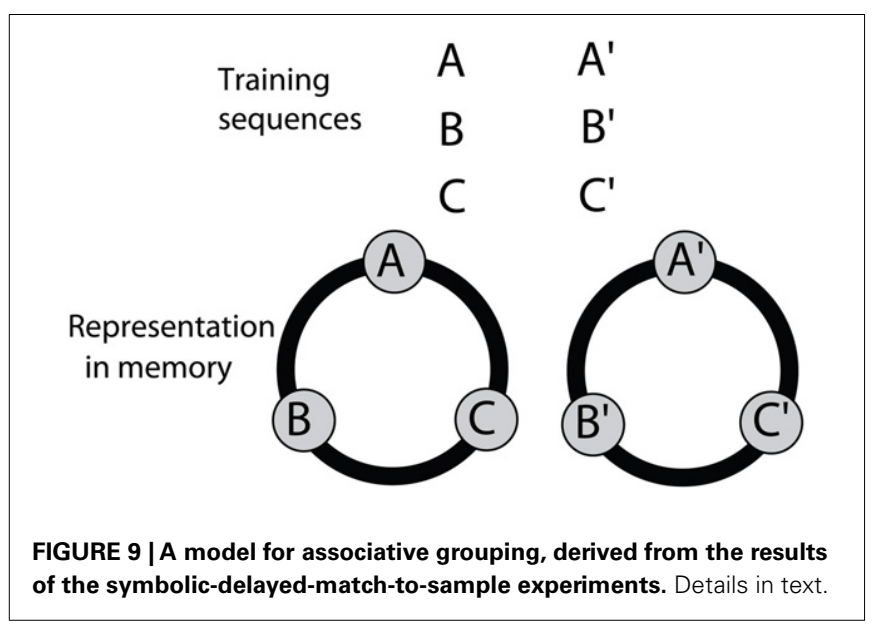

"difference." In vertebrates, the capacity to acquire such concepts has been studied using two experimental procedures, the DMTS task and the delayed non-match-to-sample (DNMTS) task (Zentall and Hogan, 1978; Holmes, 1979). The DNMTS task is similar to the match-to-sample task except that the animal is required to respond to the stimulus that is different from the sample. It should be pointed out, however, that an ability to learn the concept of "sameness" or "difference" would be proven only if the animal is able transfer the ability to correctly choose the matching (or the non-matching) stimulus to a completely novel set of stimuli, which it had not experienced during training.

Giurfa et al. (2001) examined whether honeybees could learn the concepts of "sameness" and "difference." The apparatus used in the experiments was similar to that used for the SDMTS tasks. Bees were trained on sectored and ring patterns, as shown in Figure 11A. That is, they had to learn to choose the sectored or the ring pattern in the decision chamber, according to whether the sample stimulus at the entrance was the sectored or the ring pattern. The bees learned this task well, showing a clear ability to choose the matching stimulus in each case (Figure 11C, lefthand panel). The trained bees were then subjected to a transfer test, as shown in Figure 11B, where the stimuli were two colors, blue and yellow. The bees were immediately able to transfer the matching task to the colors, despite the fact they had never been trained on them (Figure 11C, right-hand panel). They were also able to transfer the matching ability to other novel stimuli, such as gratings oriented at $+45^{\circ}$ and $-45^{\circ}$ (data not shown).

Bees can also be trained to match odors, and can immediately transfer the learned matching ability to colors. Thus, the concept of "matching," once learned, can be transferred even across sensory modalities.

Finally, bees can also learn the concept of "difference." That is, they can be trained to choose the non-matching stimulus, rather than the matching one. Figure 12A shows learning curves obtained in two experiments investigating this capability. In one experiment, the training stimuli were colors (blue and yellow). Here, bees had to learn to choose yellow in the decision chamber when they encountered blue at the entrance, and vice versa. In another experiment, the training stimuli were linear gratings, oriented 
A Training and test odor to color
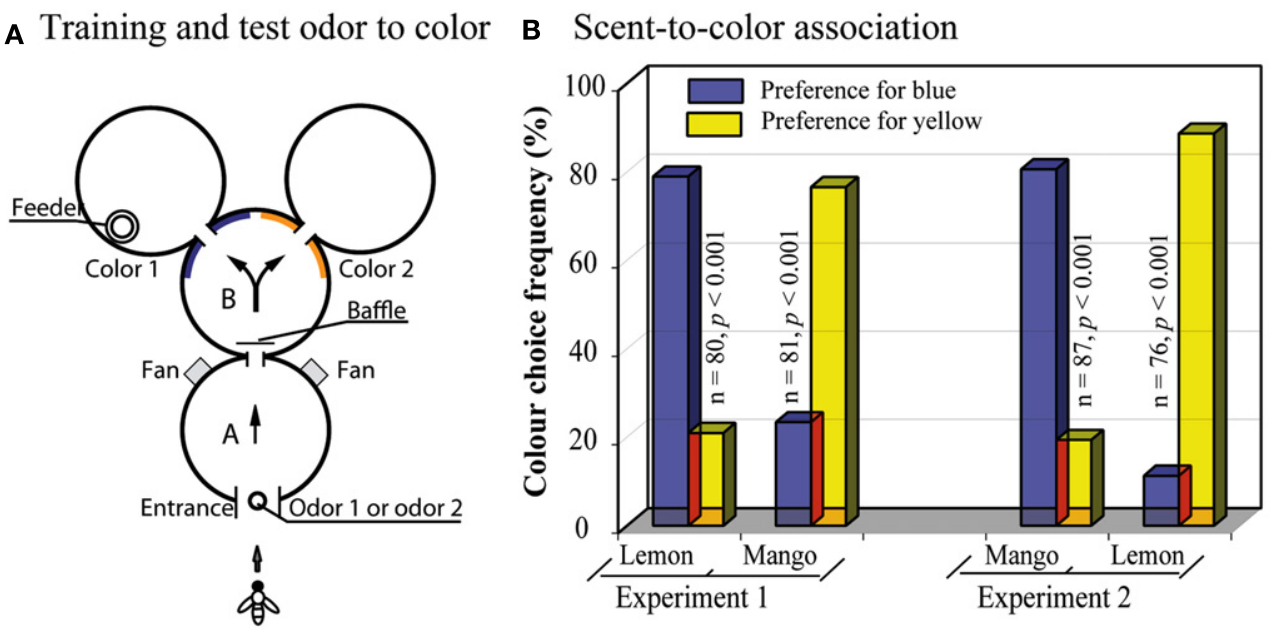

c Training and test color to odor

D Color-to-scent association
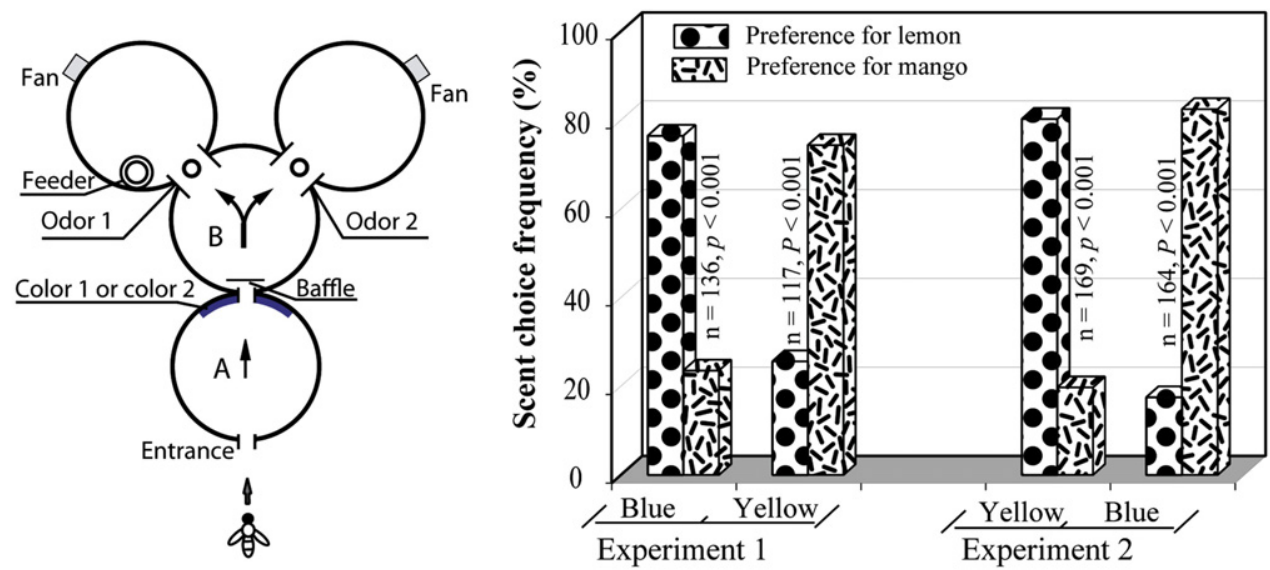

FIGURE 10 | Learning a symbolic-delayed-matching-to-sample task across the sensory modalities. (A) $Y$-maze setup with odor presentation in the first chamber. (B) Results of the scent-to-color association tests. (C)
$Y$-maze setup with color presentation in the first chamber. (D) Results of the scent-to-color association tests. Modified from Srinivasan et al. (1998). Details in text. horizontally and vertically. There, bees had to learn to choose the vertical grating in the decision chamber when they encountered a horizontal grating at the entrance, and vice versa. It is evident from Figure 12A that the bees learned both non-matching tasks well. Furthermore, in each case the trained bees were immediately able to transfer the learned, non-matching concept to novel stimuli. Bees trained on the colors were able to perform non-matching on the gratings, and vice versa (Figures 12B,C).

These findings demonstrate that bees can indeed learn rather abstract concepts, such as "sameness" and "difference," and apply them to novel situations - situations on which they have not directly been trained.

\section{CONTEXTUAL CUES IN DECISION MAKING}

Beside the aforementioned ability of bees to learn abstract rules and categorize objects, bees can use the context in which a stimulus appears to produce an appropriate response. Contextual cues are dependent on the external environment, and the animal's internal motivation. They can facilitate memory retrieval, when the context in which the memory was encoded is replicated. Thus, context cues help to carve up the world into distinct regions, and help animals cope with possible confusions (Colborn et al., 1999; Fauria et al., 2002; Cheng, 2005; Dale et al., 2005). Collett and Kelber (1988) found in their study that honeybees can retrieve the right landmark memory by the context in which the landmark is placed. Bees can also change their response to a visual pattern according to whether the stimulus provides access to the hive or the feeder (Gadagkar et al., 1995). Dale et al. demonstrated that honeybees and bumblebees can learn to treat the same visual and olfactory target in different ways in various spatial, temporal, or motivational contexts. Such contextual influences are important because they allow bees to flexibly adapt to many different situations (Dale et al., 2005). Context learning can be seen as the complementary strategy to categorization: While categories contain different objects or situations that elicit the same behavioral response, the context in which an object or situation is encountered can alter the behavioral response to it. A bee can learn, for example, that dandelions contain nectar in the morning, but not in 


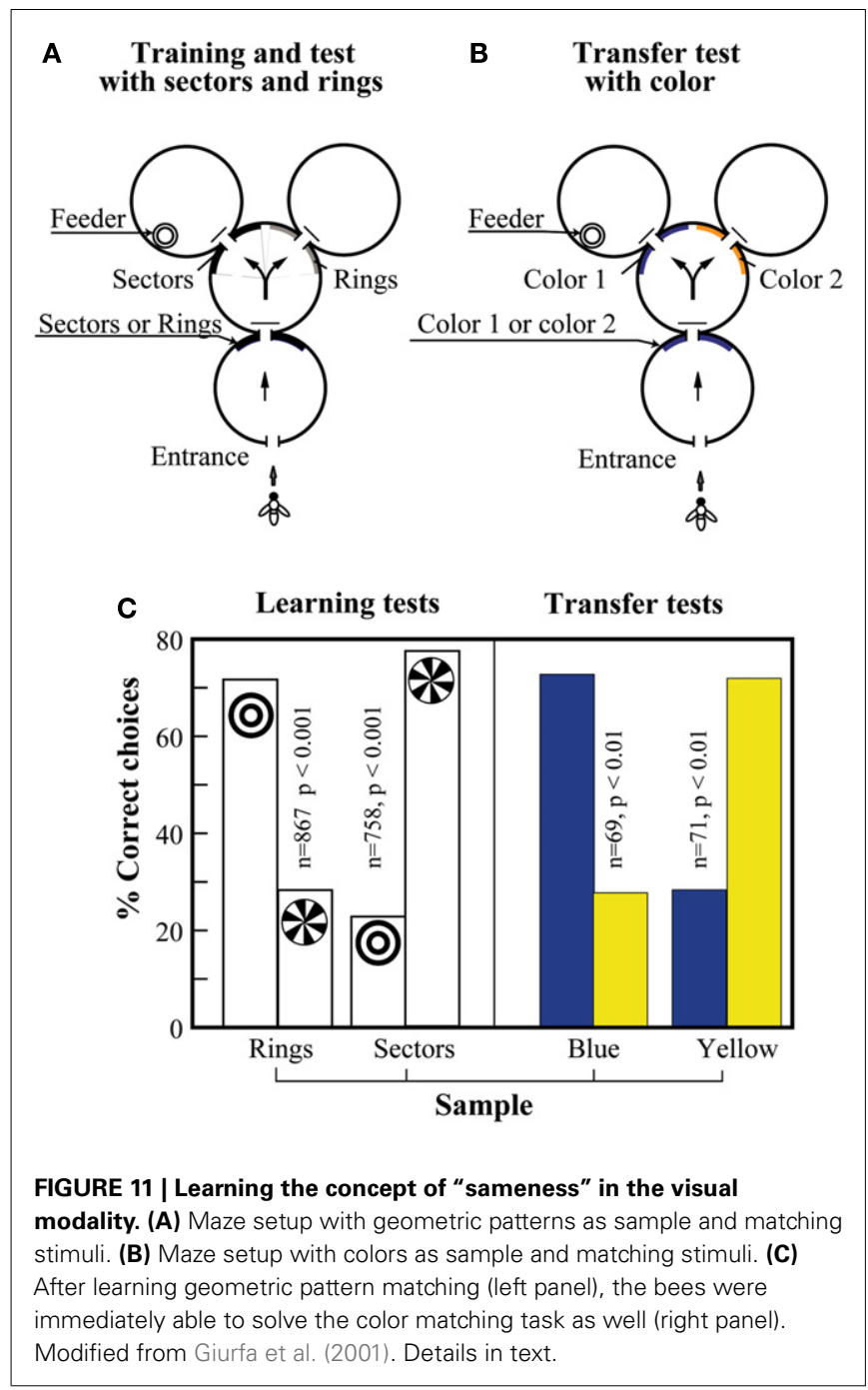

the afternoon. Thus, using the time of day as a context, a honeybee forager will land on a dandelion flower in the morning, but ignore it in the afternoon, and keep searching for clover, which provides nectar in the afternoon but not in the morning.

\section{Honeybees know what to do when}

How time and motivation can act as contextual cues was investigated by Zhang et al. (2006). In this study, bees were trained to forage in a Y-maze, where they had to choose between two competing visual stimuli in order to collect a sugar reward. When returning to the hive, the bees had to make another decision between two stimuli in order to gain entry to the nest and deliver the sugar they had collected.

In a first series of experiments, the bees learned to reverse their stimulus preference between the morning and the afternoon, i.e., following a midday break and an overnight break. They learned this quickly in two configurations: with identical and also with dissimilar stimuli at the hive and the feeder, demonstrating that the time of day can act as a contextual cue, so that a bee can treat the same stimulus differently according to the time at which it is encountered.

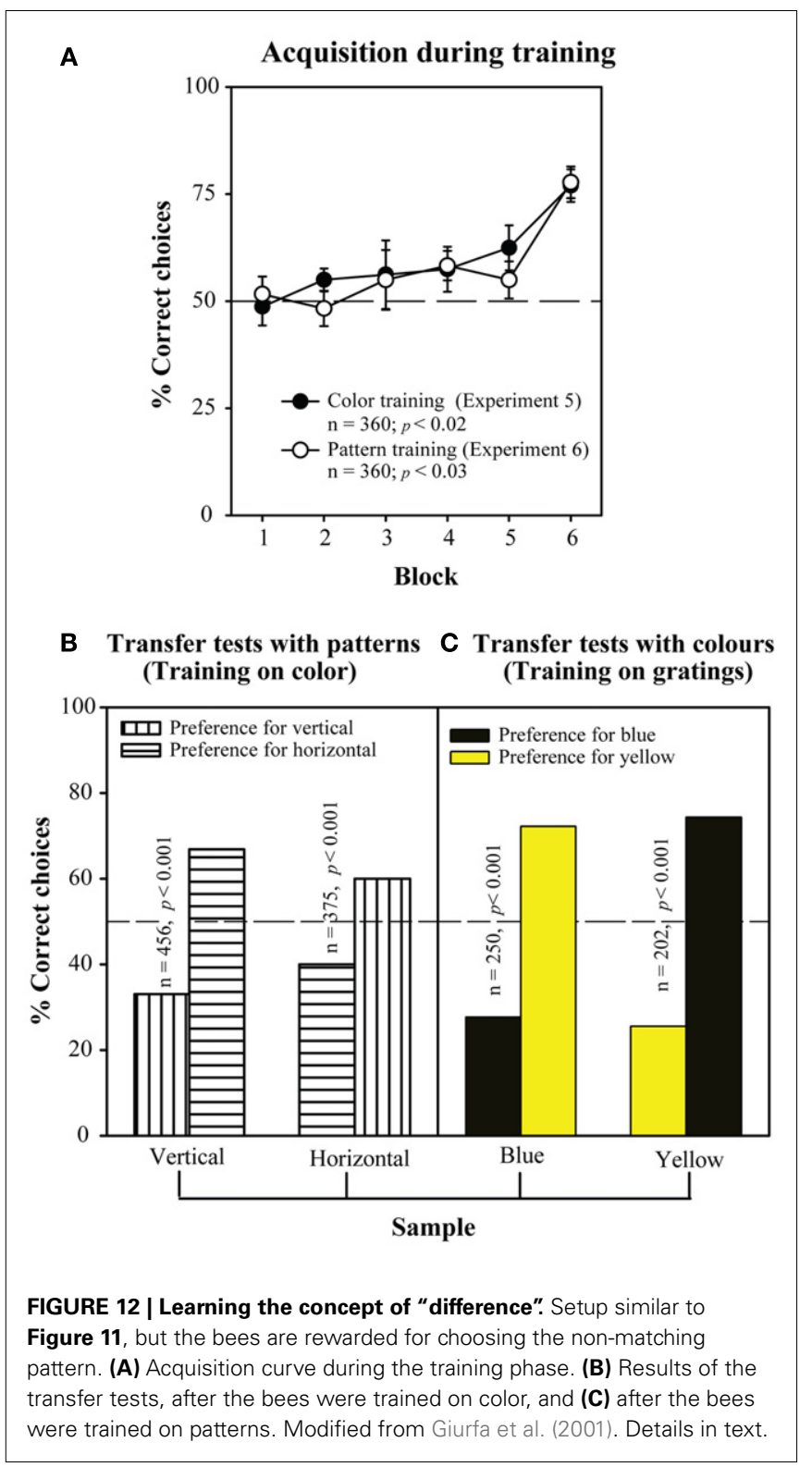

In the second series of experiments, the bees were trained to choose a yellow stimulus in the maze to get a sugar reward, and a blue stimulus in order to enter the hive. Since maze and hive were less than $10 \mathrm{~m}$ apart, the time between a decision for yellow in the maze, and the subsequent decision for blue at the hive was just about $2 \mathrm{~min}$. This demonstrates that bees can use task as a context as well: when foraging, the bee prefers yellow. On the way home, however, she changes her stimulus preference within just a few minutes, and preferentially chooses blue at the hive. This experiment was repeated with reversed colors, and showed the same result.

In the third experimental series, the bees were trained to choose a horizontal grating stimulus in the rewarded maze in the morning, and a vertical grating stimulus in the afternoon. At the same time, in order to find access to the hive, the foragers had to decide for 
the opposite configuration at the hive: the vertical grating granted access in the morning, and in the afternoon, the horizontal grating marked the open entrance. Figure 13 shows that the bees could solve even this very complicated task: they reversed their stimulus preference based on the time of day between morning and afternoon. At the same time, the task at hand acted as contextual cue, and enabled the bees to make opposing decisions within just a few minutes, when foraging and returning to the hive.

This study shows that bees can use time as a contextual cue, setting two competing visual stimuli in different contexts, while simultaneously observing a task-dependent rule (i.e., choosing A at the feeder and $\mathrm{B}$ at the hive in the morning, and $\mathrm{B}$ at the feeder and $\mathrm{A}$ at the hive in the afternoon). The experimental bees learned to treat the two stimuli differently in the morning and in the afternoon, as well as when flying to the feeder and returning to the hive. The training imposed a learnt stimulus preference on the bees' circadian rhythm (Figure 13), demonstrating that honeybees possess a sophisticated memory which is able to memorize tasks within a temporal context (Zhang et al., 2006). They could use this ability to treat stimuli differently during navigation to a food source and on the way back to the hive, as well as during for aging on at least two different times of the day, in order to be at the right place at the right time. "Planning" activities within a temporal and spatial frame of reference could enable foragers to use resources more efficiently.

\section{Circadian timed episodic-like memory: how to do the right thing in the right place at the right time}

Pahl et al. (2007) further investigated how bees use context cues to separate conflicting stimuli, in order to produce efficient foraging

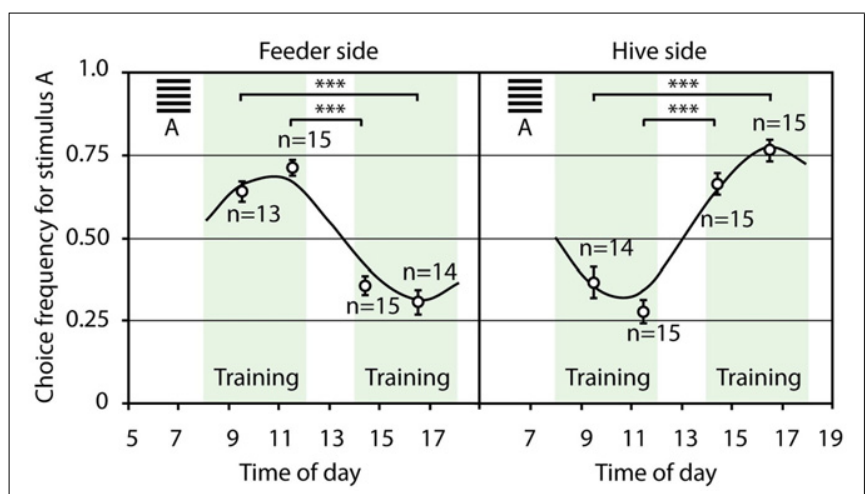

FIGURE 13 | Time and task as contextual cues. During training, the horizontal grating stimulus in the maze and the vertical grating at the hive were rewarded in the morning, whereas in the afternoon, the vertical grating in the maze and the horizontal grating at the hive were rewarded. Shown are the choice frequencies for the horizontal grating stimulus. The trained bees reversed their stimulus preference in the maze and at the hive entrance following midday breaks, as well as overnight breaks. At the same time, the bees reversed their stimulus preference within a few minutes, and made opposing decisions between foraging and homing. The modulation of the average choice frequency, with reference to the horizontal grating, could be approximated very well by a sinusoidal curve with a frequency of 0.52 , i.e., a period of $12 \mathrm{~h}$. The phase of the sinusoidal curve at the hive was shifted $180^{\circ}$ with reference to the feeder.

***Denotes $p<0.001$. Modified from Zhang et al. (2006). behavior. To study how the color, shape, and location of stimuli could be memorized within a time frame, bees were trained to forage at two Y-mazes at equal distances, but in different directions, from the hive. Maze A presented blue horizontal (rewarded) vs vertical gratings in the afternoon, while maze B presented yellow vertical (rewarded) vs horizontal gratings in the morning (the stimuli are shown in Figure 14). The bees quickly learned to fly to the active maze at the right time, and chose the rewarded stimulus with an accuracy of about $83 \%$. With this as a baseline, several transfer tests were carried out, in which color and shape properties of the stimuli were removed, and the location of the test maze was changed systematically. In this way, the relative importance of different stimulus properties could be investigated. During training, the bees memorized information about the color and shape of stimuli, but also about the location of the maze and the time of day when it provided a reward. In transfer test 1 in the mazes' original locations $\mathrm{A}$ and $\mathrm{B}$, the color cues were removed by presenting the bees with black-and-white gratings. The bees chose the previously rewarded grating orientations without the color cue, according to the maze location, and the time of day, in about $75 \%$ of the visits. In the next step, the location cue was removed by dismantling mazes $A$ and $B$, and setting up a new maze at a neutral point $C$ between the training mazes. When the bees visited the new maze and the training stimulus configuration was presented (transfer test 2, Figure 14A), the foragers chose the yellow vertical grating in the morning and the blue horizontal stimulus in the afternoon with an accuracy of $83 \%$. In transfer test 3 , the orientation and location cues were eliminated by presenting the bees with vertical blue and yellow gratings in the morning, and horizontal blue and yellow gratings in the afternoon. The bees chose the color according to the time of day, with high accuracy of about $91 \%$ (Figure 14B). In the last test, color and location cues were removed by presenting black gratings in the neutral maze C. In this situation, the bees chose the orientation according to the time of day, at a frequency of correct choices of about $72 \%$.

The results suggest that color and shape are the most important visual cues when bees decide between flowers. The absence of the spatial cue did not impair the bees' performance; they still showed a significant preference for the rewarded stimulus according to the time of day (Figures 14A-C). When visiting different feeding sites, or even when a new flower patch is discovered, previous experience enables bees to choose the most profitable flower according to the time of day (Pahl et al., 2007).

Visual and olfactory properties are not the only cues separating different flower species. Flowers open and close their blossoms at regular times during the day, as the Swedish taxonomist Carl von Linné observed more than 250 years ago (Linné, 1751). Moreover, it is not only the opening and closing times of blossoms that follow a circadian pattern. Beutler and Kleber found that the amount and concentration of nectar varies over time in a species-typical way (Beutler, 1930), and the same is true for pollen (Parker, 1925). Thus, time is a factor of great importance for nectar and pollen collectors (von Frisch, 1967). Bees would profit from a time sense not only to compensate for the sun's movement during the waggle dance, but also in order to visit the flowers during their peak nectar- and pollen-production times. This sense of time was first described by August Forel, who found bees waiting at his coffee 
table just before breakfast and afternoon tea in anticipation of sweet marmalade (Forel, 1910). His observation inspired further

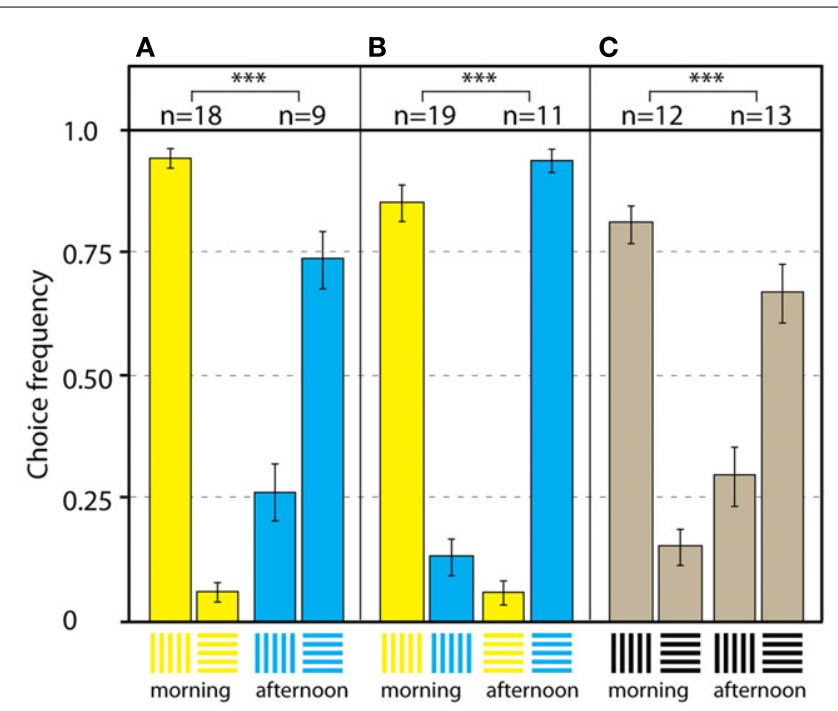

FIGURE 14 |What to do where and when. Results of the transfer tests in the neutral location. (A) Transfer test 2 with yellow and blue training patterns. The bees preferred the yellow vertical stimulus in the morning, and the blue horizontal stimulus in the afternoon. (B) Transfer test 3 with yellow and blue patterns in the same orientation. The bees preferred the yellow stimulus in the morning, and the blue stimulus in the afternoon. (C) Transfer test 4 with black patterns. The bees preferred the vertical grating in the morning, and the horizontal grating in the afternoon. $n$ Denotes number of individual bees in each test; bars are means \pm SEM. ${ }^{* *}$ Denotes $p<0.001$. Modified from Pahl et al. (2007). investigation of the bees' biological clock by von Frisch's student Behling (1929) and later by Koltermann (1971), who found that he could train bees to remember up to nine different times during a day when he presented a scented sucrose feeder.

The ability of honeybees to integrate elements of circadian time, place, and visual information shown in Pahl et al.'s (2007) study is akin to the episodic-like memory demonstrated in food caching scrub-jays (Clayton and Dickinson, 1998), and has therefore been named circadian timed episodic-like memory.

\section{NUMBER-BASED DECISION MAKING IN HONEYBEES}

Numerical abilities are an important marker in the cognitive abilities of an animal. So far, mainly vertebrate species like pigeons (Koehler, 1941) and monkeys (Brannon and Terrace, 2000) have been tested for the ability to make number-based decisions, and few convincing accounts for invertebrates exist so far (Chittka and Geiger, 1995; Franks et al., 2006; Dacke and Srinivasan, 2008). Gross et al. (2009) set out to shift the balance more in favor of the invertebrates. Honeybees, by virtue of their other impressive cognitive features, are prime candidates for investigations of this nature. Using the DMTS paradigm, the limits of the bees' ability to match two visual stimuli solely on the basis of the shared number of present elements were tested. After the experimental animals had learned the basic DMTS task in a modified Y-maze, they were able to discriminate patterns containing two or three elements. To make sure that the experimental bees were indeed using the amount of objects on a stimulus to make a decision, a series of experiments was carried out. Firstly, to exclude direct visual matching of the stimuli, the positions of the objects in sample and matching stimuli was randomized. The bees could still match two and three in all configurations (Figure 15A). The next step was

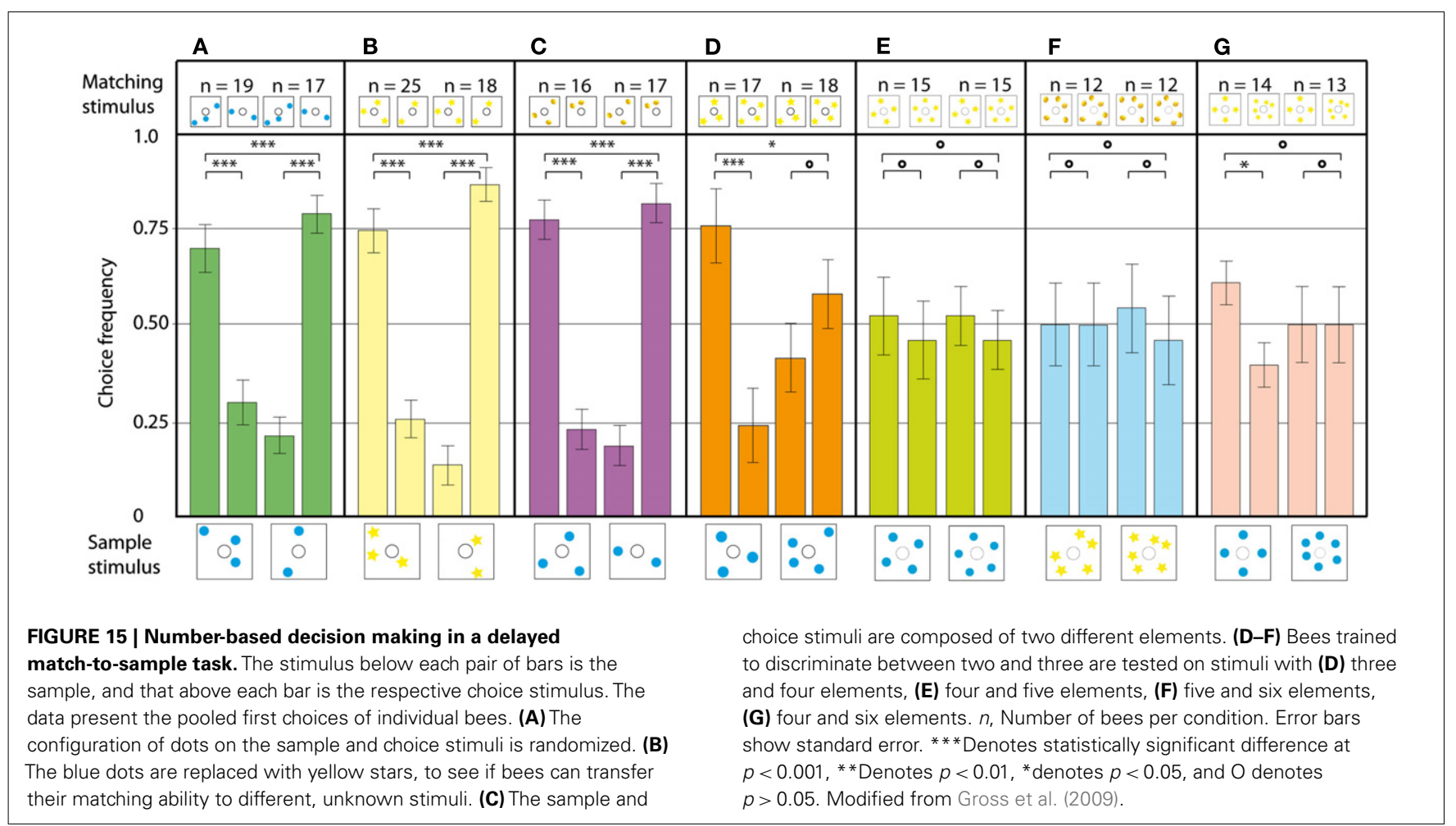


to present the bees with novel objects, which they had never seen before in training. The animals solved this task very well, demonstrating the ability to transfer the matching rule even to novel objects (Figure 15B). In the following experiment, the bees' ability to generalize over different objects was tested by using blue dots in the sample stimulus, and yellow lemons in the matching stimulus (Figure 15C). Even in this configuration, the bees had no trouble matching the stimuli based on number. When the bees were tested on a novel numerosity, a four to four match, the performance dropped significantly. In the three vs four configuration shown in Figure 15D, the bees could still do the three to three match, but their decisions in the four to four match were randomly distributed in two out of three experiments. In the experiments on the discrimination of higher object numbers, such as four vs five (Figure 15E) and five vs six (Figure 15F), the decisions were randomly distributed. Interestingly, when the bees were tested in a four vs six discrimination task, they were able to do the four to four match, but not the six to six match (Figure 15G). Thus, the bees' numerosity discrimination ability does not follow Weber's law, indicating that the animals are using absolute number, and not relative amount of objects, to discriminate between the stimuli. A series of control experiments confirmed that the bees were not using lower order cues such as the color or configuration of elements, combined area, or edge lengths of elements, spatial frequency of the stimuli, or illusory contours formed by the elements.

There are two basic mechanisms to assess the exact number of objects in a stimulus: subitizing and true counting. True counting requires subjects to (1) produce a standard sequence of number tags, (2) apply a unique number tag to each item to be counted, (3) remember what already has been counted, and (4) know that the last number tag tells how many objects are there (von Frisch, 1971). This is clearly not what the bees were doing in our experiment. Subitizing is the instant recognition of the number of objects without sequential counting. Stanley Jevons found, in his paper from 1871, that the maximum number of beans in a box he could estimate correctly, after a brief presentation not allowing for sequential counting, was 4 . With higher numbers, the amount of errors increased rapidly (Jevons, 1871). The honeybee is the first invertebrate species where a numerical ability has been convincingly demonstrated, and the process by which it achieves numerical discrimination is most likely subitizing (Gross et al., 2009). The fact that its sense of number has a similar extent as the subitizing abilities reported for many vertebrate species, including human infants (Linnel and Fluck, 2001), hints toward a highly conserved mechanism; one quite separate from real counting (Gross, 2011). The results from this study indicate that numerosity is treated by the bees as one more primary visual feature of a scene, along with color, contrast, size, and speed (Burr and Ross, 2008; Gross et al., 2009). Data on the adaptive value of numerical competence are rare, because most studies were conducted in laboratory situations. However, there are some examples of field studies: food-hoarding robins have been shown to use information about the number of food items in a cache in the wild (Hunt et al., 2008). Lyon reported a spontaneous use of numerical information (egg counting) in a natural context, reducing the fitness costs of conspecific brood parasitism in American coots (Gallistel, 1988). Lions base the decision to attack or retreat from a group of intruders on the number of roaring individuals (McComb et al., 1994). Honeybees could use their sense of number to recognize flowers by the amount of petals (Leppik, 1953), to navigate by the number of landmarks encountered (Chittka and Geiger, 1995; Dacke and Srinivasan, 2008), or to make foraging decisions according to the number of bees already present on a blossom (Gross et al., 2009).

\section{CONCLUSION}

The experiments described above give an indication of the range of environmental cues and cognitive processes that can be used by foraging honeybees in deciding what to do in particular contexts. Bees can easily learn a cue or a rule that leads to a reward, and generalize that cue or rule to novel situations in order to continue accessing that reward. However, bees are far from being hardwired automats, and can flexibly and adaptively fine-tune their decision-making process to cope with radically different contexts and situations. Stimuli - even from different sensory modalities - that tend to co-occur in a bee's experience are grouped together and associatively recalled, while abstract concepts such as "sameness" and "number" can be readily assimilated, as possible solutions, into an individual's decision-making repertoire. Finally, bees can also deal with multiple contexts, first making one decision in one context, and then flexibly switching to the opposing decision in a different context. The resulting picture of honeybee decision making is therefore a complex one, involving not only the interpretation of environmental cues and contextdependent choices, but also input from the stored memories of past experiences.

\section{A NOTE ON INTER-INDIVIDUAL VARIABILITY IN DECISION MAKING}

In decision-making experiments with honeybees, the animals usually reach a peak at $75-85 \%$ decisions for the rewarded stimulus, while in $15-25 \%$, they choose the unrewarded stimulus. This is often seen as a failure to reach the perfect score of $100 \%$. In the bees' natural foraging environment, however, rewards are not as predictable as in behavioral experiments in the lab. In the course of a nectar-gathering season, different flowering plants are in bloom successively. Even in the course of 1 day, the profitability of resources may change between morning and afternoon. Thus, honeybees (and all other animals) constantly face the decision between foraging at a well-established, but finite resource, and searching for a new, potentially richer, but uncertain one (March, 1991). In maze experiments with honeybees, the costs of choosing the "wrong," previously unrewarded stimulus are low: the bee finds an empty feeder, is released and can re-enter the maze for another trial in a matter of minutes. Foraging in a natural environment, a previously unrewarding flower may well start producing nectar or pollen later in the day, and thus justify the occasional visit by a bee. The costs of scouting for a novel flower, however, are a lot higher: considering the uncertainty of a reward, as well as the increased risk of predation, we would expect a lower rate of behavioral variability in the bees' ecological context. Indeed, flower constancy is a well-known behavioral trait in honeybees. It was described for the first time some 2300 years ago by Aristotle, but the reason for bees to stick with one type of flower at a time is still a matter of debate (Chittka et al., 1999; Raine and Chittka, 2007; Grüter and Ratnieks, 2011). Brembs (2011) argues that animals need to 
balance the efficiency of their behaviors with variability, in order to prevent predictability. In this line of research, honeybees can be a useful model to investigate the adaptiveness of behavioral

\section{REFERENCES}

Baddley, A. D. (1983). Your Memory: A User's Guide. London: Penguin.

Behling, I. (1929). Über das Zeitgedächtnis der Bienen. J. Comp. Physiol. A Neuroethol. Sens. Neural. Behav. Physiol. 9, 63-67.

Beutler, R. (1930). Biologischchemische Untersuchungen am Nektar von Immenblumen. J. Comp. Physiol. A Neuroethol. Sens. Neural. Behav. Physiol. 12, 72-176.

Brannon, E. M., and Terrace, H. S. (2000). Representation of the numerosities 1-9 by rhesus macaques (Macaca mulatta). J. Exp. Psychol. Anim. Behav. Process. 26, 31-49.

Brembs, B. (2011). Towards a scientific concept of free will as a biological trait: spontaneous actions and decision-making in invertebrates. Proc. R. Soc. Lond. B Biol. Sci. 278, 930-939.

Burr, D., and Ross, J. (2008). A visual sense of number. Curr. Biol. 18, 425-428.

Cavanagh, P. (1991). "What's up in top-down processing?," in Representations of Vision: Trends and Tacit Assumptions in Vision Research, ed. A. Gorea (Cambridge: Cambridge University Press), 295-304.

Cheng, K. (2005). Context cues eliminate retroactive interference effects in honeybees (Apis mellifera). J. Exp. Biol. 208, 1019-1024.

Chittka, L., and Geiger, K. (1995). Can honey bees count landmarks? Anim. Behav. 49, 159-164.

Chittka, L., Thomson, J. D., and Waser, N. M. (1999). Flower constancy, insect psychology, and plant evolution. Naturwissenschaften 86, 361-377.

Chittka, L., Vorobyev, M., Shmida, A., and Menzel, R. (1993). "Bee colour vision - the optimal system for the discrimination of flower colours with three spectral photoreceptor types?" in Sensory Systems of Arthropods, ed. K. Wiese (Basel: Birkhäuser Verlag), 211-218.

Clayton, N. S., and Dickinson, A. (1998). Episodic-like memory during cache recovery by scrub jays. Nature 395, 272-274.

Colborn, M., Ahmad-Annuar, A., Fauria, K., and Collett, T. S. (1999). Contextual modulation of visuomotor associations in bumble-bees (Bombus terrestris). Proc. R. Soc. Lond. B Biol. Sci. 266, 2413-2418.

Collett, T. S. (1996). Insect navigation en route to the goal: multiple strategies for the use of landmarks. J. Exp. Biol. 199, 227-235.

Collett, T. S., and Cartwright, B. A. (1983). Eidetic images in insects their role in navigation. Trends $\mathrm{Neu}$ rosci. 6, 101-105.

Collett, T. S., Fry, S. N., and Wehner, R. (1993). Sequence learning by honeybees. J. Comp. Physiol. A Neuroethol. Sens. Neural. Behav. Physiol. 172, 693-706.

Collett, T. S., and Kelber, A. (1988). The retrieval of visuo-spatial memories by honeybees. J. Comp. Physiol. A Neuroethol. Sens. Neural. Behav. Physiol. 163, 145-150.

Dacke, M., and Srinivasan, M. V. (2008). Evidence for counting in insects. Anim. Cogn. 11, 683-689.

Dale, K., Harland, D. P., Manning-Jones, A., and Collett, T. S. (2005). Weak and strong priming cues in bumblebee contextual learning. J. Exp. Biol. 208, 65-74.

Dale, R. H. I. (1988). Spaial memory in pigeons on a four-arm radial maze. Can. J. Psychol. 42, 78-83.

D'Amato, M. R., Salmon, D. P., and Colombo, M. (1985). Extent and limits of the matching concept in monkeys (Cebus apella). J. Exp. Psychol. Anim. Behav. Process. 11,35-51.

Dyer, F. C. (2002). The biology of the dance language. Annu. Rev. Entomol. 47, 917-949.

Esch, H. E., Zhang, S. W., Srinivasan, M. V., and Tautz, J. (2001). Honeybee dances communicate distances measured by optic flow. Nature 411, 581-583.

Fauria, K., Dale, K., Colborn, M., and Collett, T. S. (2002). Learning speed and contextual isolation in bumblebees. J. Exp. Biol. 205, 1009-1018.

Forel, A. (1910). Das Sinnesleben der Insekten. München: Reinhardt, E.

Franks, N., Dornhaus, A., Metherell, B., Nelson, T., Slanfear, and Symes, W. (2006). Not everything that counts can be counted: ants use multiple metrics for a single nest trait. Proc. $R$. Soc. Lond. B Biol. Sci. 273, 165-169.

Gadagkar, G., Srinivasan, M. V., and Zhang, S. W. (1995). Contextdependent learning in honeybees. Proc. Aust. Neurosci. Soc. 6, 226.

variability, because reward situations and the costs of "wrong" decisions can be easily manipulated in experimental setups with free-flying bees.

Gallistel, C. R. (1988). Counting versus subitizing versus the sense of number. Behav. Brain Sci. 11, 585-586.

Giurfa, M., Eichmann, B., and Menzel, R. (1996). Symmetry perception in an insect. Nature 382, 458-461.

Giurfa, M., Zhang, S., Jenett, A., Menzel, R., and Srinivasan, M. V. (2001). The concepts of 'sameness' and 'difference' in an insect. Nature 410, 930-933.

Goldstein, E. B. (1989). Sensation and Perception. Belmont: Wadsworth.

Gould, J., and Gould, C. G. (1988). The Honey Bee. New York: W.H. Freeman $\&$ Company.

Greggers, U., and Menzel, R. (1993). Memory dynamics and foraging strategies of honeybees. Behav. Ecol. Sociobiol. (Print) 32, 17-29.

Gross, H. J. (2011). To bee or not to bee, this is the question ... the inborn numerical competence of humans and honeybees. Commun. Integr. Biol. 4, 594-597.

Gross, H. J., Pahl, M., Si, A., Zhu, H., Tautz, J., and Zhang, S. (2009). Number-based visual generalisation in the honeybee. PLoS ONE 4, e4263. doi:10.1371/journal.pone.0004263

Grüter, C., Balbuena, M. S., and Farina, W. M. (2008). Informational conflicts created by the waggle dance. Proc. R. Soc. Lond. B Biol. Sci. 275, 1321-1327.

Grüter, C., and Ratnieks, F. L. W. (2011). Flower constancy in insect pollinators: adaptive foraging behaviour or cognitive limitation? Commun. Integr. Biol. 4, 633-636.

Herman, L. M., and Gordon, J. A. (1974). Auditory delayed matching in the bottlenose dolphin. J. Exp. Anal. Behav. 21, 17-26.

Holmes, P. W. (1979). Transfer of matching performance in pigeons. J. Exp. Anal. Behav. 31, 103-114.

Horridge, G. A. (1996). The honeybee (Apis mellifera) detects bilateral symmetry and discriminates its axis. J. Insect Physiol. 42, 755-764.

Horridge, G. A. (1999). Twodimensional pattern discrimination by the honeybee. Physiol. Entomol. 24, 197-212.

Horridge, G. A., and Zhang, S. W. (1995). Pattern vision in honebees (Apis mellifera): flower-like patterns with no predominant orientation. J. Insect Physiol. 41, 755-764.
Horridge, G. A., Zhang, S. W., and Lehrer, M. (1992). Bees can combine range and visual angle to estimate absolute size. Philos. Trans. R. Soc. Lond. B Biol. Sci. 337, 49-57.

Hunt, S., Low, J., and Burns, K. C. (2008). Adaptive numerical competency in a food-hoarding songbird. Proc. R. Soc. Lond. B Biol. Sci. 275, 2373-2379.

Jeanson, R., Dussutour, A., and Fourcassie, V. (2012). Key factors for the emergence of collective decision in invertebrates. Front. Neurosci.

Jevons, W. (1871). The power of numerical discrimination. Nature 3 , 281-300.

Judd, S. P. D., and Collett, T. S. (1998). Multiple stored views and landmark guidance in ants. Nature 392, 710-714.

Koehler, O. (1941). Vom Erlernen unbenannter Anzahlen bei Vögeln. Naturwissenschaften 29, 201-218.

Koltermann, R. (1971). 24-Std-Periodik in der Langzeiterinnerung an Duft- und Farbsignale bei der Honigbiene. Z. Vgl. Physiol. 75, 49-68.

Lehrer, M., Horridge, G. A., Zhang, S. W., and Gadagkar, R. (1995). Shape vision in bees - innate preference for flower-like patterns. Philos. Trans. $R$. Soc. Lond. B Biol. Sci. 347, 123-137.

Leppik, E. (1953). The ability of insects to distinguish number. Am. Nat. 87, 229-236.

Lindsay, P. H., and Norman, D. A. (1977). Human Information Processing: An Introduction to Psychology. New York: Academic press.

Linné, C. V. (1751). Philosophia Botanica. Stockholm: G. Kiesewetter.

Linnel, M., and Fluck, M. (2001). The effect of maternal support for counting and cardinal understanding in pre-school children. Soc. Dev. 10, 202-220.

March, J. G. (1991). Exploration and exploitation in organizational learning. Organ. Sci. 2, 71-87

McComb, K., Packer, C., and Pusey, A. (1994). Roaring and Numerical assessment in contests between groups of female lions, Panthera Leo. Anim. Behav. 47, 379-387.

Menzel, R. (1990). "Learning, Memory, and "Cognition" in Honey Bees," in Neurobiology of Comparative Cognition, eds R. P. Kesner and D. S. Olton (Hillsdale: Lawrence Erlbaum Associates Publishers), 237-292. 
Menzel, R., and Bitterman, M. E. (1983). "Learning in Honeybees in an Unnatrral Situation," in $\mathrm{Neu}$ roethology and Behavioral Physiology, eds F. Huber and H. Markl (Berlin: Springer).

Menzel, R., Kirbach, A., Haass, W.-D., Fischer, B., Fuchs, J., Koblofsky, M., Lehmann, K., Reiter, L., Meyer, H., Nguyen, H., Jones, S., Norton, P., and Greggers, U. (2011). A common frame of reference for learned and communicated vectors in honeybee navigation. Curr. Biol. 21, 645-650.

Pahl, M., Zhu, H., Pix, W., Tautz, J., and Zhang, S. (2007). Circadian timed episodic-like memory - a bee knows what to do when, and also where. $J$. Exp. Biol. 210, 3559-3567.

Pahl, M., Zhu, H., Tautz, J., and Zhang, S. (2011). Large scale homing in honeybees. PLOS ONE 6, e19669. doi:10.1371/journal.pone.0019669

Parker, R. L. (1925). The Collection and Utilization of Pollen by the Honeybee. Ithaca, NY: Cornell University.

Pick, C. G., and Yanai, J. (1983). Eight arm maze for mice. Int. J. Neurosci. 21, 63-66.

Raine, N. E., and Chittka, L. (2007). Flower constancy and memory dynamics in bumblebees (Hymenoptera: Apidae: Bombus). Entomol. Generalis 29, 179-199.

Ritzmann, R. E., Harley, C. M., Daltorio, K. A., Tietz, B. R., Pollack, A. J., Bender, J. A., Guo, P., Horomanski, A. L., Kathman, N. D., Nieuwoudt, C., Brown, A. E., and Quinn, R. D. (in press). Deciding which way to go: how do insects alter movements to negotiate barriers? Front. Neurosci.
Riley, J. R., Greggers, U., Smith, A. D., Reynolds, D. R., and Menzel, R. (2005). The flight paths of honeybees recruited by the waggle dance. Nature 435, 205-206.

Roberts, W. A. (1972). Short-term memory in the pigeon - effects of repetition and spacing. J. Exp. Psychol. 94, 74.

Ronacher, B. (1992). Patternrecognition in honeybees multidimensional-scaling reveals a city-block metric. Vision Res. 32, 1837-1843.

Seeley, T. D., and Buhrman, S. C. (1999). Group decision making in swarms of honey bees. Behav. Ecol. Sociobiol. (Print) 45, 19-31.

Seeley, T. D., Camazine, S., and Sneyd, J. (1991). Collective decision-making in honey-bees - how colonies choose among nectar sources. Behav. Ecol. Sociobiol. (Print) 28, 277-290.

Srinivasan, M. V., Zhang, S. W., Altwein, M., and Tautz, J. (2000). Honeybee navigation: nature and calibration of the "odometer." Science 287, 851-853.

Srinivasan, M. V., Zhang, S. W., and Bidwell, N. J. (1997). Visually mediated odometry in honeybees. J. Exp. Biol. 200, 2513-2522.

Srinivasan, M. V., Zhang, S. W., and Gadakar, R. (1998). ContextDependent Learning in Honeybees. Stuttgart: Thieme.

Stroeymeyt, N. (2012). Dependence versus independence in collective decision-making. Front. Neurosci.

Van Hateren, J. H., Srinivasan, M. V., and Wait, P. B. (1990). Pattern recognition in bees: orientation discrimination. J. Comp. Physiol. A Neuroethol. Sens. Neural. Behav. Physiol. 167, 649-654

von Frisch, K. (1967). The Dance Language and Orientation of the Bees. Cambridge, MA: Harvard University Press.

von Frisch, K. (1971). Bees: Their Vision, Chemical Senses and Language. Ithaca, NY: Cornell University Press.

Wehner, R. (1971). The generalisation of directional visual stimuli in the honey bee, Apis mellifera. J. Insect Physiol. 17, 1579-1591.

Wehner, R., Bleuler, S., Nievergelt, C. and Shah, D. (1990). Bees navigate by using vectors and routes rather than maps. Naturwissenschaften 77, 479-482.

Wehner, R., Michel, B., and Antonsen, P. (1996). Visual navigation in insects: coupling of egocentric and geocentric information. J. Exp. Biol. 199, 129-140.

Wolf, L. L., and Hainsworth, F. R. (1990). Non-random foraging by hummingbirds: patterns of movement between Ipomopsis aggregato (Pursch) V. grant inflorescences. Funct. Ecol. 4, 149-157.

Zentall, T. R., and Hogan, E. (1978). Same/different concept learning in the pigeon: the effect of negative instances and prior adaptation to transfer stimuli. J. Exp. Anal. Behav. 30, 177-186.

Zhang, S., Bartsch, K., and Srinivasan, M. V. (1996). Maze learning by honeybees. Neurobiol. Learn. Mem. 66, 267-282.

Zhang, S., Lehrer, M., and Srinivasan, M V. (1999). Honeybee memory: navigation by associative grouping and recall of visual stimuli. Neurobiol. Learn. Mem. 72, 180-201.

Zhang, S., Mizutani, A., and Srinivasan, M. V. (2000). Maze navigation by honeybees: learning path regularity. Learn. Mem. 7, 363-374.

Zhang, S., Schwarz, S., Pahl, M., Zhu, H., and Tautz, J. (2006). Honeybee memory: a honeybee knows what to do and when. J. Exp. Biol. 209, 4420-4428.

Zhang, S., and Srinivasan, M. V. (1994). Prior experience enhances pattern discrimination in insect vision. Nature 368, 330-332.

Conflict of Interest Statement: The authors declare that the research was conducted in the absence of any commercial or financial relationships that could be construed as a potential conflict of interest.

Received: 06 January 2012; paper pending published: 16 April 2012; accepted: 25 May 2012; published online: 18 June 2012.

Citation: Zhang S, Si A and Pahl M (2012) Visually guided decision making in foraging honeybees. Front. Neurosci. 6:88. doi: 10.3389/fnins.2012.00088 This article was submitted to Frontiers in Decision Neuroscience, a specialty of Frontiers in Neuroscience. Copyright (C) 2012 Zhang, Si and Pahl. This is an open-access article distributed under the terms of the Creative Commons Attribution Non Commercial License, which permits non-commercial use, distribution, and reproduction in other forums, provided the original authors and source are credited. 